Tél. 80.63 .30 .02

\title{
Approche à l'échelle du système racinaire de l'absorption hydro-minérale. Conséquences en matière de modélisation.
}

\author{
R Habib 1, L Pagès 1, MO Jordan 1, T Simonneau 1, M Sébillotte 2 \\ 1 INRA, station d'agronomie, domaine Saint-Paul, 84143 Montfavet cedex; \\ 2 INA-PG, chaire d'agronomie, 16 rue Claude Bernard, 75231 Paris cedex 05, France
}

(Reçu le 24 avril 1990; accepté le 21 juin 1991)

\begin{abstract}
Résumé - Le but du travail que nous présentons est de discuter de la fonction d'absorption hydro-minérale considérée à l'échelle du système racinaire. L'approche la plus souvent utilisée consiste à attribuer à chaque élément de racine d'un système racinaire la même efficacité vis-à-vis de l'absorption pour estimer ensuite l'absorption totale par l'ensemble du système. Cette hypothèse est souvent considérée comme extrêmement simplificatrice. L'objectif principal de cette revue est de la confronter aux données actuelles de la littérature.

Dans un premier temps, nous présentons divers travaux qui permettent de juger du bien fondé de cette approche au niveau du système racinaire. En particulier, nous présentons des données sur la variabilité de l'absorption racinaire considérée à différents niveaux : le long d'une racine, entre racines, en conditions de disponibilité hydrique ou minéraie hétérogène, et dans le temps. Cette analyse permet de montrer qu'un tel niveau d'intégration paraît fondé pour aborder l'absorption racinaire de l'eau et du nitrate. Pour les autres éléments majeurs de la nutrition minérale, le problème est à raisonner au cas par cas en fonction des conditions particulières d'alimentation.

Dans un second temps, après une rapide présentation des formalismes des modèles d'absorption, nous envisageons les conséquences de l'analyse précédente en matière de modélisation macroscopique de l'absorption racinaire. Pour l'absorption d'eau, nous soulignons que la prise en compte du potentiel hydrique et de la conductance hydraulique des racines devrait constituer un progrès dans les futurs travaux de modélisation dans ce domaine. Pour l'absorption minérale, l'état des connaissances apparaît comme moins développé, par exemple le concept même de besoins minéraux reste encore mal défini, et les progrès possibles semblent moins immédiats. Différentes voies sont cependant indiquées dans le but d'améliorer les modèles actuels.
\end{abstract}

système racinaire / système sol-plante / absorption d'eau / absorption minérale / modèle macroscopique

Summary - Water and mineral uptake by the root system of plants, with special regard to modelling absorption by the roots. The review deals with the water and mineral uptake by the root system of plants. The validity of the root system approach is studied based on the concept of a root demand coefficient. The variability of net influx rates is considered in a single root and between roots, according to the variability in water and nutrient availability, and according to time. It appears that the root system approach is well adaptated to the study of water and nitrate uptake by plants. As regards other major nutrients, the particular experimental conditions have to be taken into consideration. Some consequences of these mechanisms are presented in terms of modelling water and mineral uptake by roots. Regarding water absorption, it is concluded that including plant parameters such as root water potential and hydraulic conductivity may improve water uptake modelling. As regards mineral absorption modelling, it should be noted that further research still has to be carred out, eg the concept of plant mineral requirements has not yet been fully defined. Thus the improvement of mineral uptake models appears to be more complex. Nevertheless, some ways to improve mineral uptake models have been presented in this review. 


\section{INTRODUCTION}

Les études sur le système racinaire des plantes sont moins développées que celles sur le système aérien, notamment celles qui concernent les plantes cultivées considérées au champ (Greenwood et al, 1982). Récemment, un effort important a été réalisé qui porte à la fois sur la modélisation de la croissance et du développement d'un système racinaire et de la structure $\left(^{*}\right)$ qui en résulte (Pages et Aries, 1987, 1988; Diggle, 1988; Pages et al, 1989) et sur la modélisation de l'absorption hydrominérale (Barber et Silberbush, 1984; Novak, 1987; Habib et Lafolie, 1991). Par ailleurs certains travaux ont montré qu'il existait des interactions fortes entre ces 2 aspects, distribution spatiale des racines et $a b-$ sorption hydrique et minérale. Ainsi, Tardieu (1984, 1987, 1988a, b) a clairement démontré que la distribution spatiale du système racinaire in situ ne pouvait être négligée si on voulait pouvoir appréhender, au champ, l'absorption hydrique d'un couvert de maïs.

II n'existe pas, à notre connaissance, de synthèse bibliographique sur les relations entre la structure du système racinaire (et la distribution spatiale qui en résulte) et l'absorption hydrominérale à l'échelle du système racinaire. Ce sont certaines de ces relations que nous présentons ici en tentant de montrer comment on peut en intégrer les résultats dans des modèles de fonctionnement macroscopiques conçus à l'échelle du système racinaire. Pour juger du bien-fondé des hypothèses introduites dans ce type de modèle de fonctionnement, nous serons conduits à rappeler brièvement certains mécanismes physiologiques qui régissent l'absorption hydro-minérale. II existe, concernant ces mécanismes, d'importantes revues bibliographiques récentes (Grignon et Touraine, 1981; Touraine et Grignon, 1981; Boyer, 1985; Passioura, 1988), auxquelles le lecteur pourra se référer.

Nous avons abordé dans une même revue des problèmes relatifs à l'absorption de l'eau et ceux relatifs à l'absorption minérale. Nous pensons en effet que, au moins à l'échelle agronomique, il est difficile d'appréhender les problèmes de nutrition minérale sans tenir compte, dans le même temps, de ceux posés par l'ali- mentation hydrique. Mais, les phénomènes de transport de la sève brute (Taylor et Klepper, 1978) ne seront pas envisagés car ils demanderaient d'analyser le fonctionnement de la plante entière, définissant un cadre trop large pour une même revue bibliographique. Nous n'aborderons pas, non plus, l'effet de mycorhizes sur le fonctionnement racinaire (Clarkson et Hanson, 1980; Clarkson, 1985; Smith et Gianinazzi-Pearson, 1988), ni les problèmes de coût énergétique de l'absorption hydro-minérale (Lambers et al, 1983; Clarkson, 1985; Daie, 1985), qui compliqueraient singulièrement cette étude au niveau où nous la concevons. Pour la même raison, le cas des légumineuses qui ont une double source d'alimentation azotée ne sera pas non plus envisagé.

Les travaux sur l'absorption racinaire que nous serons amenés à présenter ont mis en œuvre des méthodes d'étude variées (culture hydroponique, sur substrat, inerte ou non, en sol) qui peuvent avoir des implications différentes en terme de fourniture hydrique et minérale et d'approvisionnement racinaire. De même, l'absorption a été étudiée à des niveaux divers (racine excisée, racine isolée mais rattachée à la plante entière, système racinaire subdivisé ou non) dont on sait (Blanchet et al, 1974) qu'elles jouent sur l'expression quantitative du phénomène observé. Cette diversité des approches rend parfois difficile la synthèse de ces travaux. Nous préciserons donc les conditions expérimentales quand cela nous paraîtra nécessaire à une meilleure compréhension des résultats présentés.

\section{POSITION DU PROBLĖME}

L'approche à l'échelle du système racinaire de l'absorption hydro-minérale est basée sur le concept de capacité d'absorption racinaire (CAR). Cette grandeur caractérisant l'efficacité racinaire (masse absorbée par unité de racine et par unité de temps) est estimée expérimentalement, et est donc liée aux conditions de l'expérimentation. Classiquement, les paramètres définissant l'efficacité sont déterminés par des essais où l'on mesure, pour une période donnée, les quantités absorbées par une plante ou un couvert végétal, et où l'on ramène celles-ci, par le calcul (c'est-à-dire une division), à l'unité de

\footnotetext{
- Nous inspirant de la terminologie proposée par Girardin et al (1986) pour décrire le système racinaire d'un pied de maïs, en la généralisant au cas des systèmes racinaires pivotants, nous appellerons racine une racine allongée ramifiée ou non, réseau racinaire l'ensemble des racines portées par une racine d'ordre 1 (racine primaire de maïs, ou pivot d'un pêcher, par exemple), et système racinaire l'ensemble des réseaux racinaires (un seul réseau donc dans le cas d'un système racinaire pivotant non taillé). Le terme de structure racinaire sera pris au sens de l'organisation du système racinaire dans l'espace.
} 
racine (unité de longueur, par exemple) et à l'unité de temps. Ainsi, l'absorption est supposée identique entre les racines d'un même système racinaire et tout au long de celles-ci. Ces hypothèses, sur lesquelles sont basées la majorité des modèles rendant compte de l'absorption des systèmes racinaires, sont souvent considérées comme extrêmement simplificatrices (Picard, 1988). Et l'un des objectifs principaux de cette revue est de le confronter aux données actuelles de la littérature.

La CAR est, par la définition que nous venons d'en donner, une valeur moyenne qui n'a de sens que par référence au système étudié. Pour la généraliser, on peut considérer le système formé par la plante entière. La CAR optimale, CAR', est alors celle pour laquelle la croissance obtenue est maximale pour le génotype considéré (c'est-à-dire qu'il n'y a pas de facteur limitant). Cette utilisation de la croissance maximale comme point repère de la CAR ${ }^{\circ}$ rejoint celle faite par Greenwood (1976) pour quantifier le niveau d'un stress azoté.

Cependant, il faut noter qu'expérimentalement il est possible, et même fréquent, d'estimer des CAR inférieures (existence d'au moins un facteur limitant la croissance) ou supérieures (consommation de luxe) à la $\mathrm{CAR}^{\circ}\left(^{*}\right)$. En outre, la croissance de la plante entière n'est pas liée de façon univoque à celle des parties racinaires (par exemple, les relations d'allométrie entre organes aérien et souterrain varient en fonction des conditions environnementales : Brouwer et De Wit, 1969; Brouwer, 1981; Brouwer, 1983), et il n'est pas possible de contrôler l'ensemble des facteurs de production. Le concept de $\mathrm{CAR}^{\circ}$ est donc difficilement utilisable en pratique.

II est plus aisé de rechercher expérimentalement une valeur maximale de la CAR, CARm, sans référence au potentiel de croissance de la plante entière, et d'étudier l'écart à la CARm induit par la modification de divers facteurs de production. Dans cette définition, la CARm n'est pas un maximum absolu, qu'il peut être vain de rechercher, mais la plus grande valeur obtenue expérimentalement. II faut noter qu'il n'existe pas de relation simple entre CARm et CARo. Cependant, en l'absence de consommation de luxe, la CARm doit, par définition, tendre vers la CAR ${ }^{\circ}$ quand on réduit le nombre de facteurs limitant la croissance de la plante.
L'objectif des travaux sur la nutrition hydrominérale en agronomie est de prévoir, pour un état donné du peuplement végétal, ou parfois de la plante isolée, considéré dans son environnement (stade de développement, climat, disponibilité des ressources), quelle est la quantité de l'élément considéré qui va être absorbée et d'en déduire éventuellement des pratiques correctives (fertilisation, ou modalités d'irrigation par exemple). C'est donc bien au niveau du système racinaire que se situe notre problématique. Cela pose cependant un certain nombre de questions quant à l'utilisation du concept de CAR :

- est-il fondé d'intégrer le long d'une même racine (une racine primaire, par exemple) l'absorption des différentes parties, présentant des degrés variés de différenciation, qui la composent?

- est-il fondé d'intégrer au sein d'un système racinaire l'absorption des différentes racines (des racines primaires et leurs ramifications secondaires, par exemple) qui le composent?

- quelle est la réponse du système racinaire à la variation, et à la variabilité, des états du milieu?

Les éléments de réponse que nous pouvons apporter à ces questions seront discutés au chapitre suivant. Nous en examinerons ensuite les conséquences en matière de modélisation de l'absorption racinaire.

\section{EST-IL FONDÉ D'ÉTUDIER L'ABSORPTION HYDRO-MINÉRALE AU NIVEAU DU SYSTÈME RACINAIRE ?}

\section{Rappel succinct des mécanismes de l'absorption racinaire}

Parmi les différentes fonctions assurées par un système racinaire, nous nous sommes donc plus particulièrement intéressés à l'absorption hydro-minérale qui peut être définie par le prélèvement de l'eau et des ions du milieu par l'ensemble des racines constituant le système racinaire, et leur pénétration dans la plante qui se ferait principalement par le plasmalemme des cellules corticales (Anderson, 1975; Grignon et Touraine, 1981; Touraine et Grignon, 1981), suivie de leur conduction vers la stèle (Weatherley,

\footnotetext{
* Son estimation est cependant possible en laboratoire sous certaines conditions expérimentales où l'on maîtrise le flux d'éléments nutritifs arrivant aux racines en maintenant la plante à son niveau de teneur optimale pour tous les éléments considérés (Ingestad, 1982).
} 
1975; Touraine et Grignon, 1981) par la voie apoplasmique (notamment $\mathrm{Ca}^{2+}, \mathrm{Mg}^{2+}, \mathrm{Sr}^{2+}$ ) ou symplasmique (notamment $\mathrm{K}^{+}, \mathrm{Cl}^{-}, \mathrm{H}_{2} \mathrm{PO}_{4}^{-}$, $\left.\mathrm{NO}_{3}^{-}\right)$.

L'absorption hydrique est actuellement considérée comme un phénomène exclusivement passif (Weatherley, 1975; Touraine et Grignon, 1981; Passioura, 1988) prenant son origine dans la différence de potentiel hydrique entre le milieu extérieur (sol, solution nutritive) et le xylème. Le flux total d'absorption hydrique est généralement séparé en 2 composantes additives, l'une reliée au gradient de potentiel osmotique, pondéré d'un terme de réflexion membranaire, et l'autre reliée au gradient de pression hydrostatique (Weatherley, 1975; Dalton et al, 1975; Fiscus, 1977). Pour chacune de ces composantes, le flux hydrique est donné par le produit du gradient de pression par un terme traduisant la résistance du tissu à l'écoulement, que l'on désigne sous le terme de conductivité hydraulique radiale de la racine :

$$
Q=k(\mathrm{~d} P-\sigma \mathrm{d} \omega)
$$

où :

$Q$ est le flux hydrique $\left(\mathrm{m}^{3} \cdot \mathrm{s}^{-1}\right)$

$k$ est la conductivité hydraulique $\left(\mathrm{m}^{3} \cdot \mathrm{s}^{-1} \cdot \mathrm{Pa}^{-1}\right)$ $\mathrm{d} P$ est la différence de pression hydrostatique (Pa)

$\sigma$ est le coefficient de réflexion membranaire $\mathrm{d} \omega$ est la différence de pression osmotique ( $\mathrm{Pa}$ )

Cette conception des transferts d'eau dans une plante offre l'intérêt majeur de permettre d'utiliser un même formalisme, basé sur les mêmes relations phénoménologiques, pour exprimer la continuité du processus physique dans le système sol-plante-atmosphère (Molz, 1981).

Concernant l'absorption des ions, la situation apparaît comme plus complexe. Le flux d'absorption des ions est généralement considéré comme un processus actif couplé directement avec une dépense énergétique par la plante (Russel et Barber, 1960; Brouwer, 1965; Grignon et Touraine, 1981; Callot et al, 1982). II peut, en fait, être décomposé en 2 termes additifs, l'un traduisant un transport passif par diffusion et convection des solutés, et l'autre traduisant un transport actif (Dalton et al, 1975).

Les cinétiques globales d'absorption des ions en fonction de la concentration en sel présentent généralement, aux faibles concentrations (inférieures à $1 \mathrm{mmol} . \mathrm{I}^{-1}$ ), l'allure d'une hyperbole rectangulaire que l'on a interprétée comme traduisant l'intervention d'un transporteur (Epstein et Hagen, 1952). Quand la concentration de la solution au contact des racines est augmentée à des valeurs supérieures à $1 \mathrm{mmol} . \mathrm{I}^{-1}$, on observe très généralement une reprise de l'absorption qui a été interprétée comme indiquant la mise en œuvre d'un second mécanisme d'absorption (dual mechanism). Epstein (1976) note l'existence de ces doubles isothermes pour $\mathrm{K}^{+}$, $\mathrm{NH}_{4}{ }^{+}, \mathrm{Na}^{+}, \mathrm{Ca}^{2+}, \mathrm{Mg}^{2+}, \mathrm{Fe}^{2+}, \mathrm{Cl}-, \mathrm{Br}, \mathrm{H}_{2} \mathrm{PO}_{4}^{-}$. Rao et Rains (1976), Bretelier et Nilsen (1982) l'ont observé pour $\mathrm{NO}_{3}-$. Mais, Grignon et Touraine (1981) soulignent que la situation semble être plus complexe. Et la théorie du double transporteur est encore l'objet de débats (Lassales et Thellier, 1974; Kochian et Lucas, 1982; Nissen, 1989 ) et un transport passif par diffusion est parfois évoqué pour les fortes concentrations (Kochian et Lucas, 1982).

Le formalisme le plus souvent retenu est analogue à celui de la cinétique enzymatique :

$$
v=V_{\max } C /\left(C+K_{m}\right)
$$

où :

$\checkmark$ est le taux réel d'absorption (mol.s $\mathrm{s}^{-1} \cdot \mathrm{U}^{-1}$ de racines)

$V_{\max }$ est le taux maximal (mol.s $\mathrm{s}^{-1} \cdot \mathrm{U}^{-1}$ de racines)

$C$ est la concentration de la solution (mol. I $^{-1}$ )

$K_{m}$ est la valeur de la concentration telle que $v=$ $V_{\max } / 2$

\section{Variabilité de l'absorption le long d'une racine}

Chez la quasi-totalité des plantes vasculaires, les racines présentent entre le cortex et la stèle une différenciation morphologique et anatomique (voir la revue très complète de Clarkson et Robards, 1975), l'endoderme. La différenciation longitudinale de l'endoderme est fondamentale de par son influence sur le flux apoplasmique (Clarkson et Robards, 1975; Weatherley, 1975; Touraine et Grignon, 1981). La distance à l'apex de l'endoderme différencié varie en fonction de l'espèce, quelques $\mathrm{mm}$ chez l'orge (Clarkson, 1968; Ferguson et Clarkson, 1975) et le pommier (Atkinson, 1980), quelques $\mathrm{cm}$ chez le maïs (Ferguson et Clarkson, 1975), et du type de racines, séminale, nodale ou latérale, chez l'orge (Clarkson et Robards, 1975).

Par ailleurs, des travaux récents, réalisés pour l'instant sur céréales, ont souligné le rôle particulier joué par la maturation des vaisseaux de mé- 
taxylème (à 10-15 cm de l'apex chez l'orge, à 20$30 \mathrm{~cm}$ de l'apex chez le maïs) à la fois sur l'absorption de l'eau (Mac Cully et Canny, 1988) et sur l'absorption minérale (Mac Cully et al, 1987; Huang et Van Steveninck, 1988).

Concernant l'absorption hydrique, la conductance hydraulique radiale des racines est un paramètre très discuté, tant par les valeurs qui lui sont attribuées en fonction de l'espèce végétale considérée et des conditions de mesure (Newman, 1973), que par leur possible variabilité le long d'une racine (racine secondaire de fève: Brouwer, 1954; racine primaire de maïs : Maertens, 1971a). La conductance hydraulique radiale varierait ainsi le long de la racine (Hansen, 1974) et pourrait dépendre de l'organisation anatomique des tissus (Mac Cully et Canny, 1988; Steudle, 1989). Touraine et Grignon (1981), Passioura (1988) considèrent que la conductance hydraulique radiale d'une racine est indépendante de l'intensité du flux de transpiration, bien que ce point soit encore débattu (Dainty et al, 1981; Morizet et al, 1988; Passioura, 1988). Les données actuelles permettent de penser que l'essentiel du flux hydrique se ferait préférentiellement par voie symplasmique (Hanson et al, 1985; Swietlik, 1989). Comme le notaient Mac Cully et Canny (1988), la majeure partie des travaux rapportés dans la littérature concernent de jeunes racines, le plus souvent non ramifiées et excisées, et les valeurs de conductance racinaire radiale mesurées sont de l'ordre de $10^{-7} \mathrm{~cm}^{3} \cdot \mathrm{s}^{-1} \cdot \mathrm{MPa}^{-1} \cdot \mathrm{cm}^{-1}$ de racine (variant de 0,5 à $30 \times 10^{-7}$ selon les espèces et les conditions expérimentales). À partir des résultats de Maertens (1971a) obtenus sur une racine de maïs âgé de 2 mois et demi rattachée à la plante, on peut calculer (Mac Cully et Canny, 1988) une valeur de l'ordre de $50 \times 10^{-7}$ pour la partie apicale et $300 \times 10^{-7}$ $\mathrm{cm}^{3} \cdot \mathrm{s}^{-1} \cdot \mathrm{MPa}^{-1} \cdot \mathrm{cm}^{-1}$ de racine pour la partie basale, donc notablement supérieures aux valeurs précédentes.

Ces dernières données sont cohérentes avec la conception d'une absorption hydrique s'effectuant tout le long de la racine (Maertens, 1971a; Clarkson et Robards, 1975; Mac Cully et Canny, 1988), le flux hydrique étant à relier à la conductance axiale, elle-même liée à la puissance quatrième du rayon des vaisseaux de xylème (Taylor et Klepper, 1978). Mac Cully et Canny (1988) calculent que le rapport théorique des conductances axiales, et donc des flux hydriques, est de 1 à 4000 entre la zone racinaire à métaxylème non mature (proche de l'apex) et celle où il est ouvert au flux xylémique. Ils en concluent, conformé- ment aux résultats de Maertens (1971a) et aux spéculations de Clarkson et Robards (1975), que l'essentiel de l'absorption hydrique doit avoir lieu dans la partie âgée du système racinaire. Ces résultats ont été confirmés par les travaux de Wenzel et al (1989) sur des semis de diverses plantes en $\mathrm{C}_{4}$. Notons cependant que la résistance axiale au flux hydrique (dans le $x y$ lème) est souvent considérée comme négligeable. Ainsi Baldwin (1976) estime qu'elle est inférieure de 100 à 1000 fois à la résistance radiale, et ne la prend en compte que pour des racines d'une longueur supérieure à $25 \mathrm{~cm}$. Klepper (1990) note que la conductance axiale est rarement limitante chez les racines de dicotylédones du fait de la croissance secondaire, mais qu'elle peut l'être chez les monocotylédones. Les résultats de Wenzel et al (1989) montrent cependant que la résistance axiale au flux hydrique ne peut être négligée pour de jeunes plantules.

Les connaissances dans ce domaine évoluent actuellement très rapidement, et vont clairement dans le sens d'une reconnaissance de la fonction d'absorption hydrique des parties âgées du système racinaire.

Concernant l'absorption des ions, la mise en place de l'endoderme différencié influe directement sur les capacités racinaires d'absorption des ions qui empruntent la voie apoplasmique, par exemple le calcium (Clarkson et Robards, 1975) mais également le magnésium (Touraine et Grignon, 1981) et le strontium (Clarkson, 1968; Touraine et Grignon, 1981); mais non sur l'absorption des ions circulant par voie symplasmique. Dès 1968, Clarkson avait monté en utilisant du ${ }^{32} \mathrm{P}$ que le phosphate était absorbé avec la même intensité par la partie apicale (premier $\mathrm{cm}$ ) ou basale (à $44 \mathrm{~cm}$ de l'apex) d'une racine séminale d'orge âgée de 3 semaines. L'endoderme différencié ne constituait donc pas une barrière à l'entrée des ions dans la stèle (Russel et Clarkson, 1976). Ce résultat est maintenant admis pour le potassium, le nitrate, le phosphate, l'ammonium et le chlore (Touraine et Grignon, 1981; concernant spécifiquement le potassium, voir la revue de Russel et Clarkson, 1971). Ainsi, l'ancienne théorie des zones apicales absorbantes n'est vérifiée que pour les ions obligés d'emprunter la voie apoplasmique (Touraine et Grignon, 1981). Par ailleurs, les résultats de Russel et Clarkson (1971), portant sur des racines d'orge et d'aubergine rattachées à la plante, indiquaient que la zone apicale n'était pas, non plus, la zone la plus active. Les travaux 
de Maertens (1971a), sur l'absorption d'eau, d'azote et de potassium par les parties apicale ou basale d'une racine de maïs rattachée à la plante entière, ont également montré une plus grande activité de la zone basale, reliée probablement à une plus grande intensité du flux de sève brute (Maertens et Clauzel, 1980). Par contre, si la racine était excisée, le schéma plus connu d'une plus grande activité apicale était obtenu (Maertens, 1971a). Cependant, les travaux récents de Ernst et al (1989) sur l'absorption de 32P par différentes zones (âgées de 1 à 26 jours) d'une racine apicale de maïs cultivé sur sol en minirhizotron indiquent une plus grande activité apicale que basale $(30 \%$ de l'activité apicale).

Les résultats que nous venons de présenter ont été obtenus pour la plupart en solution nutritive. Le schéma de fonctionnement qui peut en être déduit (absorption symplasmique sur toute la longueur de la racine, ou apoplasmique dans les parties apicales pour les ions exclus du symplasme) peut être perturbé quand l'absorption est étudiée pour une plante poussant dans un sol. Bosc (1981), Bosc et Maertens (1981) ont montré, par exemple, que l'alimentation phosphorique, et en grande partie l'alimentation potassique, de tomates cultivées en pots dans un volume limité de sol, étaient en relation étroite avec la vitesse de croissance journalière des racines, même pour de forts niveaux d'enrichissement en ces éléments. Dès que les racines cessaient de s'allonger, l'absorption du potassium était pratiquement stoppée, et celle du phosphore nettement ralentie. Les travaux d'Atkinson (1974) portant sur la cinétique d'absorption de $32 \mathrm{P}$ par des pommiers in situ vont tout à fait dans le même sens. Ces résultats indiqueraient donc qu'en conditions de sol c'est l'approvisionnement des racines qui est le facteur limitant leur absorption. Ainsi, pour les ions absorbés par la voie symplasmique, mais présentant de fortes interactions avec la matrice solide, tout se passe comme si seules les parties apicales des racines étaient actives. L'hypothèse la plus probable est que les apex en croissance exploitent alors de nouvelles zones de sol non encore appauvries par leur fonctionnement; ceci étant bien sûr à moduler en fonction de la richesse du milieu en ces éléments.

En outre, il faut noter le rôle particulier de réservoir que semblent jouer, au moins chez les céréales, les vaisseaux de métaxylème non matures (Mac Cully et al, 1987; Huang et Van Steveninck, 1988). Mac Cully et Canny (1988) cal- culent, pour le potassium, que cette réserve vacuolaire du métaxylème pourrait contribuer, pour du maïs au stade floraison, pour environ $10 \%$ à la fourniture totale de potassium par la plante (exprimée en mg.j ${ }^{-1}$ par plante), l'essentiel de l'absorption de $\mathrm{K}^{+} \mathrm{se}$ faisant alors par les parties âgées des racines primaires ou par les racines latérales qu'elles portent.

Les connaissances dans ce domaine vont donc également clairement dans le sens d'une reconnaissance de la fonction d'absorption minérale des parties âgées du système racinaire.

\section{Variabilité de l'absorption entre racines d'un même système racinaire}

Les propriétés d'absorption hydro-minérale sont également susceptibles de varier entre les racines d'un même système racinaire (Barley, 1970; Bhat, 1982). Dans un premier paragraphe nous évoquerons l'influence du milieu sur l'architecture racinaire, en ce qu'elle complique notablement l'interprétation des travaux que nous rapporterons au second paragraphe sur l'influence du type de racines sur l'absorption d'eau et d'éléments minéraux.

Certains auteurs ont étudié les variations des capacités d'absorption des racines en fonction de leur position dans l'architecture du système racinaire (nature séminale ou nodale, ordre, diamètre, âge, etc). Comme le souligne Hackett (1969), ces études sont motivées par l'espoir de trouver des relations entre caractéristiques morphologiques et capacité d'absorption, afin de pouvoir, par la suite, moduler les propriétés des racines en fonction de leur position architecturale. Mais, il faut noter que, ces travaux sont particulièrement difficiles à mener car il existe de fortes interactions entre les conditions de milieu que l'on étudie (concentration en solutés, potentiel hydrique) et l'expression architecturale du système racinaire. Par ailleurs, les corrélations de croissance entre les différentes parties du système étudié viennent encore compliquer l'interprétation de ces travaux. Les études ont été menées, en ce qui concerne l'effet concentration en solutés (culture en solution nutritive ou sur substrat inerte), en faisant varier la concentration de l'ensemble de la solution nutritive (May et al, 1965), ou seulement d'un ou plusieurs de ses éléments, généralement $N, P$ et $K$ sont étudiés, ou parfois seulement 2 de ces éléments, (Hackett, 1969, 1972; Drew, 1975; Foehse et Jungk, 1983). En ce qui concerne l'effet potentiel hydri- 
que, celui-ci est abordé souvent en culture en pots, en irrigant les plantes à des régimes différents (Fitter, 1986), en augmentant progressivement l'humidité du sol jusqu'à la saturation, ou en le laissant se dessécher progressivement (Vartanian, 1975 et 1981); plus rarement ces études ont été menées in situ (Taylor et Klepper, 1974). Par ailleurs, on peut se réferer à des revues bibliographiques portant plus spécifiquement sur ces sujet (Jordan, 1987; Pages, 1988). Tous ces travaux montrent qu'il existe une relation entre l'architecture du système racinaire (intensité de l'élongation et de la ramification, topologie du réseau racinaire) et les conditions physiques et physico-chimiques prévalant dans le milieu racinaire (humidité, potentiel hydrique, composition ionique de la solution). Ces modifications de l'architecture sont considérées comme l'expression de l'adaptation des systèmes racinaires à un environnement lui-même variable pour une meilleure exploitation des ressources disponibles* (Robinson et Rorison, 1983; Fitter, 1987; Pages, 1988).

À notre connaissance, il n'y a dans la littérature que très peu de travaux sur la variabilité de la conductance hydraulique racinaire radiale en fonction du type de racines. Notons cependant que Sands et al (1982, cité par Klepper, 1990) ont montré que les zones subérisées de racines de pins avaient une conductance de l'ordre de $40 \%$ de celle des jeunes racines. Dans leur étude bibliographique Tardieu et Manichon (1986) concluent qu'il n'y a pas de critère morphologique pour distinguer des racines selon leur capacité d'absorption hydrique.

II en est autrement en ce qui concerne la conductivité axiale (Passioura, 1972 et 1974; Meyer et Alston, 1978; Taylor et Klepper, 1978; Fowkes et Landsberg, 1981; Hamblin et Tennant, 1987; Klepper, 1990). Celle-ci dépend, en effet du nombre et du diamètre des vaisseaux de $x y-$ lème qui varient en fonction de la position architecturale de la racine considérée (Torrey et Wallace, 1975; Fowkes et Landsberg, 1981; Fitter, 1987; Pages, 1988; Klepper, 1990).

Maertens (1971b), étudiant l'absorption d'azote, de phosphore et de potassium par des racines de maïs cultivé en solution nutritive concluait que, pour chaque élément étudié, les différences observées, en fonction de la nature séminale ou adventive des racines, n'étaient pas significatives. Russel et Clarkson (1971) considè- rent de façon générale, sur la base d'essais en solution nutritive où l'absorption et la translocation de $\mathrm{K}^{+}$(pour l'orge et la courge) étaient étudiées pour des segments de racines rattachés à la plante entière que, pour le potassium, tout le système racinaire possède des propriétés équivalentes pour l'absorption et le transport de cet élément. Atkinson (1980, 1985), dans ses revues bibliographiques sur les arbres fruitiers, considère également que toutes les parties du système racinaire, ligneuses ou non, sont capables d'absorber, même s'il peut exister des différences d'efficacité entre les différentes parties. II rapporte même, dans le cas de l'absorption de ${ }^{32} \mathrm{P}$ par des racines de cerisier, que de jeunes racines blanches ou des racines ligneuses (de diamètre plus important) présentaient les mêmes capacités d'absorption si on les exprimait par unité de surface de l'épiderme. Russel et Sanderson (1967) pour P et Sr, Hackett (1969) pour P, Russel et Clarkson (1976) pour $P$ et $K$ (et non pour $\mathrm{Ca}$ ) avaient obtenu des résultats du même ordre sur orge en comparant l'efficacité de racines séminales, nodales ou latérales exprimée par unité de volume racinaire.

Là encore, les données de la bibliographie vont dans le sens d'une activité d'absorption minérale de l'ensemble du système racinaire. Et il n'existe pas, à notre connaissance, de résultats démontrant clairement une contribution particulière de certains types de racines à l'alimentation de la plante. À cet égard, le travail de compilation effectué par Brewster et Tinker (1972) est particulièrement intéressant. II indique que, pour une large variété de plantes (mono- et dicotylédones, annuelles et pérennes), de type de racines considérées (zone apicale, mais rattachée à la plante, ou système racinaire entier) et de conditions expérimentales (de la culture hydroponique au sol) les CAR pour $N, P, K$ varient de moins d'un ordre de grandeur, et souvent beaucoup moins si on restreint la comparaison à des conditions expérimentales proches.

\section{Variation de l'absorption racinaire en fonction de l'âge de la plante}

Selon la définition que nous en avons donnée dans l'introduction de ce travail, la CAR pour l'eau va varier en moyenne comme I'ETR, en fonction de l'indice foliaire du couvert végétal et

\footnotetext{
* Nous ne défendons pas là l'idée d'un chimiotropisme positif qui ne peut d'ailleurs être appuyée sur des expérimentations en solution nutritive comme celles que nous rapportons, mais plus simplement l'existence d'interactions entre la composition de la solution et la croissance et le développement du système racinaire.
} 
de la demande climatique. Ceci est bien sûr sommaire compte tenu des connaissances actuelles sur les mécanismes qui régissent l'absorption hydrique. Nous reviendrons sur ce point au chapitre suivant quand il s'agira de définir les variables explicatives introduites dans les modèles de fonctionnement.

Concernant l'absorption minérale, on ne dispose pas d'un schéma de fonctionnement aussi clairement établi, car la notion de besoin en éléments minéraux reste souvent mal définie (Sébillotte, 1985). Maertens (1971b) n'a pas trouvé, pour le maïs, de différences significatives de l'absorption racinaire en fonction de l'âge des plantes, de 8 à $45 \mathrm{j}$. Par contre, Nielson et Barber (1978), Ningping et Barber (1985) ont observé une diminution au cours du temps de l'efficacité de l'absorption de phosphore par des plantules de blé en solution. Cette diminution ne pouvait être attribuée au seul vieillissement des racines, et les auteurs indiquaient que l'efficacité des jeunes racines avait également diminué. Les estimations faites par Barraclough (1986), au champ, de l'évolution au cours du temps des influx nets (en mmol.s ${ }^{-1} . \mathrm{cm}^{-1}$ de racine) de $\mathrm{N}, \mathrm{P}$, $\mathrm{K}, \mathrm{Ca}, \mathrm{Mg}$ par des cultures de blé à fort potentiel de rendement, montrent, globalement, que ceuxci augmentent de février à avril-mai (selon les conditions de culture), puis décroissent pour atteindre en juin des valeurs du même ordre que celles de février.

Ce point, sur la variation au cours du temps des capacités d'absorption racinaire, est particulièrement important chez les végétaux pérennes. Les quelques données actuellement disponibles chez les arbres fruitiers tendent à montrer, au moins pour le nitrate, qu'il existe une variation saisonnière de l'efficacité du système racinaire (Grasmanis et Nicholas, 1971; Weinbaum et al, 1978; Bhat, 1983; Atkinson, 1985; Habib, 1987; Wallach et al, 1990) que l'on a parfois pu relier au stade de développement phénologique (Weinbaum et al, 1978) et qui semble s'adapter à la cinétique de croissance (Weinbaum et al, 1990). Dans le cas des travaux présentés par Habib (1987) et Wallach et al (1990), le système racinaire avait été très fortement rabattu à la plantation (cultures menées respectivement en solution nutritive et sur sable) de telle sorte que la quasi-totalité du système racinaire soit constitutée de racines ayant poussé en cours d'expérimentation. La variation observée de la CAR ne peut donc pas être attribuée au turn-over du chevelu racinaire, mais plus probablement à une régulation de la CAR en relation avec les besoins de croissance de la plante (Habib, résultats non publiés).

\section{Variation de l'absorption racinaire en condition de milieu à disponibilité hétérogène}

En matière de nutrition hydro-minérale, 2 modalités d'approvisionnement sont à envisager (Blanchet et al, 1974; Habib, 1988) : le déplacement des éléments vers la racine, phénomène prépondérant pour l'eau et les ions mobiles dans le sol tel $\mathrm{NO}_{3}^{-}$(Robinson et Rorison, 1983; Habib et Lafolie, 1988); la croissance des racines, les amenant à exploiter un plus grand volume de sol, pour les ions peu mobiles $\left(\mathrm{PO}_{4}^{3-}\right.$, et $\mathrm{K}^{+}$ou $\mathrm{NH}_{4}^{+}$à un moindre titre), comme cela a été montré dans des revues bibliographiques (Clarkson et Hanson, 1980; Clarkson, 1985) ou dans des modèles de fonctionnement (Barber et Silberbush, 1984; Barraclough, 1989; Jungk et Claassen, 1989). Par ailleurs, l'ensemble des conditions édaphiques et culturales (Vartanian, 1975; Fitter, 1987; Tardieu et Manichon, 1987), ainsi que les caractéristiques génétiques de l'espèce végétale considérée (Cannon, 1949; Taylor et Klepper, 1978; Kuiper, 1983) vont finalement aboutir à une certaine occupation du sol, caractérisée par la distribution spatiale des racines.

L'ensemble de ces phénomènes qui définissent l'approvisionnement des racines va avoir une influence déterminante sur l'absorption hydro-minérale. En particulier, même si on considérait à un instant donné que le champ des disponibilités hydrique et minérale du sol est uniforme, une répartition spatialement hétérogène du système racinaire va induire dans le temps, de par le fonctionnement même des racines, une distribution non uniforme de ces disponibilités (surtout si la vitesse d'approvisionnement est limitante). Quand les techniques de culture induisent elles-mêmes une hétérogénéité du champ des propriétés physico-chimiques du milieu édaphique (interaction croissance $x$ propriétés physiques), cet effet est encore plus marqué (ex irrigation localisée fertilisante, travail du sol induisant des zones de compacité contrastée). Ainsi, bien que la majorité des travaux sur l'absorption racinaire ait porté sur des conditions de disponibilité homogènes, ou supposées telles, l'absorption en conditions hétérogènes est le cas le plus fréquent au champ.

À l'échelle macroscopique des volumes de sol et des racines qu'ils contiennent, les quantités 
d'eau absorbées peuvent varier avec les conditions de fourniture hydrique. En conditions irriguées, par exemple, l'irrigation par aspersion et l'irrigation goutte-à-goutte constituent 2 techniques de fourniture opposées. Lorsque la disponibilité de l'eau diminue pour une partie du système racinaire, l'absorption y est également réduite, aussi bien dans le sol (Lascano et van Bavel, 1984) qu'en solution nutritive (Lawlor, 1973; Papadopoulos et al, 1985; N'DaKouassi et Puard, 1989). Lorsqu'on procède à l'ablation d'une partie du système racinaire de maïs cultivé en solution, on peut observer une augmentation de la capacité d'absorption hydrique des racines restant rattachées à la plante (Brouwer, 1981). La baisse de la conductivité hydraulique du milieu (qui peut réduire de plusieurs ordres de grandeur l'approvisionnement en eau des racines) ne peut pas être seule invoquée. De plus, dans les situations de disponibilité non uniforme auxquelles on aboutit fréquemment, la relation entre disponibilité de l'eau et absorption racinaire ne semble pas être stable. L'absorption d'eau par une partie du système racinaire dépend notamment de la disponibilité pour le reste du système (Brouwer, 1953; Michel et Eisharkawi, 1970; West, 1978a, b; Morizet et al, 1988; Simonneau et Habib, 1990). Dans certains cas, la transpiration n'est pas modifiée lorsqu'on prive une partie du système racinaire d'approvisionnement hydrique par ablation (Teskey et al, 1985) ou par isolement (Morizet et al, 1988). Dans des travaux similaires, on observe par contre une réduction de l'absorption, mais qui n'est cependant jamais aussi forte que la diminution de la quantité de racines dont l'approvisionnement n'est pas limitant (Kirkham et al, 1969; Tan et al, 1981; Briggs et Wiebe, 1982).

Ces résultats sont souvent interprétés en termes de modifications locales des capacités d'absorption des racines dont les potentialités sont supposées très largement supérieures aux absorptions couramment observées (Callot et al, 1982). Cependant, les mécanismes physiologiques qui permettent d'accroître l'absorption des racines dans ces conditions de disponibilité hydrique hétérogène ne sont pas encore connus. À l'échelle de la plante entière, on ne sait pas comment se répercute la demande des parties aériennes sur un système racinaire en place dans un sol à disponibilité hydrique hétérogène, et comment se fait la régulation entre les différentes parties du système racinaire. Actuellement, 2 hypothèses peuvent être évoquées : une augmentation de la conductance hydraulique (Morizet et al, 1988) ou une diminution locale du potentiel hydrique des racines bien alimentées en eau (Simonneau et Habib, 1990).

Plus généralement, si la CAR locale est un maximum à un moment donné, y aurait-il une $\mathrm{CAR}^{\mathrm{m}}$ variable, régulée par la plante en fonction des états du milieu, ou une $C A R^{m}$ génétique dont une fraction plus ou moins importante serait utilisée selon les circonstances?

Un certain nombre d'auteurs ont étudié l'influence de conditions de milieu hétérogènes sur l'absorption minérale (Drew et Saker, 1975; Frith et Nichols, 1975; Maertens et Clauzel, 1975a, b; Edwards et Barber, 1976; Claassen et Barber, 1977; Drew et Saker, 1978; Maertens, 1978; de Jager, 1982, 1984; Abbott et Cough, 1986). Ces travaux ont permis d'aborder l'étude de la relation entre disponibilité minérale et absorption racinaire quand une partie plus ou moins importante du système racinaire se trouvait en conditions d'alimentation limitante. Ces études ont abouti à la conclusion que si on sépare le système racinaire en un compartiment bien alimenté et un autre limitant en l'élément étudié, les capacités d'absorption des racines bien alimentées augmentent de façon très notable. Maertens (1971b) avait d'ailleurs inféré, comparant l'absorption minérale de maïs cultivé en solution aux exportations d'une culture conduite sur sol argileux, que moins du dixième du système racinaire de la plante in situ pouvait assurer ses besoins si l'approvisionnement n'était pas limitant; concluant que c'était la faible disponibilité des éléments nutritifs dans un sol qui impliquait la nécessité d'une fonction d'absorption répartie sur une beaucoup plus grande masse de racines ne travaillant qu'à une fraction de leur potentiel.

Mais, les mécanismes physiologiques qui permettent d'accroître l'absorption des racines en présence d'une source d'engrais localisée ne sont pas encore connus. Considérant la plante entière, on ne sait, de même que pour l'absorption hydrique, s'il s'agit d'une CARm fixée génétiquement.

\section{Conclusion : dans quelles conditions est-on fondé à utiliser la notion de CAR ?}

Pour l'eau, quand la disponibilité en cet élément (limitante ou non) est uniformément répartie dans le sol (fourniture hydrique homogène, pluie ou irrigation par aspersion et approvisionnement 
uniforme), les données présentées montrent que I'on peut définir une CAR et que la variation temporelle de la CAR peut être, le plus souvent, ramenée à la variation de l'indice foliaire et de la demande climatique. Par contre, quand il existe une hétérogénéité spatiale de la disponibilité hydrique, il est des cas où la différence d'absorption observée laisse penser qu'il y a eu régulation (au moins apparente) de la CAR. Nous verrons au chapitre suivant que cette régulation peut parfois être expliquée par une modification des conditions physiques de l'absorption qu'il est aisé de modéliser. Il est des cas, par contre, où les mécanismes de régulation ne sont pas clairement identifiés et où, en l'état des connaissances, la notion de CAR ne peut être appliquée (un bon exemple en est donné par le travail de Morizet et al, 1988).

Concernant l'absorption minérale, il est clair que pour les ions absorbés par la voie apoplasmique, la notion d'efficacité moyenne n'a pas de sens, sauf à admettre que l'essentiel de la longueur racinaire est constitué par des parties apicales en croissance. Ainsi, dans la majorité des cas, il ne nous paraît pas fondé d'utiliser la notion de CAR. On peut bien sûr penser restreindre cette approche à des parties du système racinaire ayant un comportement semblable (pour exemple : l'ensemble des zones apicales), mais cela n'est pas sans poser d'importants problèmes expérimentaux, de mesure et de localisation spatiale des zones considérées.

Pour les ions absorbés par la voie symplasmique, la notion de CAR prend, par contre, tout son sens, à condition que l'approvisionnement (difficulté de diffusion des éléments minéraux dans le sol) n'induise pas une relation apparente entre zone apicale (correspondant à une zone de sol non encore appauvrie) et absorption minérale. Ainsi, le calcul d'une CAR paraît bien adapté au cas du nitrate, mais doit être envisagé avec beaucoup de précaution pour le potassium et les phosphates, en fonction, en particulier, des propriétés physico-chimiques du substrat.

La variation temporelle de la CAR ne pose de problème particulier que dans le cas de l'absorption minérale. Et on ne sait, pour l'instant, procéder autrement qu'en estimant expérimentalement l'évolution temporelle de la CAR (Wallach et al, 1990).

En conclusion de ce chapitre, nous sommes amenés à considérer que la modélisation de l'absorption racinaire à l'échelle du système racinaire ne peut être raisonnablement entreprise que dans le cas de l'eau et du nitrate. Pour les autres ions majeurs absorbés par la voie symplasmique (phosphate et potassium), les fortes interactions qu'ils présentent avec la matrice du sol font qu'il est difficile d'envisager une approche aussi globale. II est d'ailleurs significatif de constater que, après les essais de fertilisation $P$ et $K$ de longue durée (Gachon, 1988) qui ont montré que les plantes absorbent d'autres formes minérales que $K$ échangeable ou $P$ assimilable, la majorité des travaux actuels concernant ces ions portent sur l'étude des interactions sol-racines à l'échelle de la rhizosphère (par exemple, Marschner, 1990).

\section{MODÉLISATION DE L'ABSORPTION D'EAU ET DE NITRATE À L'ÉCHELLE DU SYSTĖME RACINAIRE}

Dans ce chapitre, nous faisons référence aux modèles macroscopiques décrivant l'absorption d'eau et de nitrate dans un sol.

Concernant l'eau, une revue détaillée de ces modèles peut être trouvée dans l'article de Molz (1981). Le principe général en est de répartir la transpiration entre les couches de sol proportionnellement à la fraction du système racinaire présente dans cette couche. L'absorption d'eau est alors le plus souvent calculée à partir de la différence de potentiel hydrique sol-racine, parfois pondérée par des facteurs correctifs tenant compte des résistances au transfert d'eau dans le sol et/ou la plante.

Concernant le nitrate, les modèles utilisés dans la littérature sont, pour la plupart, dérivés de le relation de Epstein et Hagen (1952). Ce formalisme présente l'intérêt de pouvoir simuler, par la même équation, 2 types de comportements souvent observés in situ : une absorption dépendant linéairement de la concentration, pour les faibles concentrations (de l'ordre de 10-5 mol.. ${ }^{-1}$ ), et une absorption quasi indépendante de la concentration, pour les concentrations plus élevées (de l'ordre de $10^{-4} \mathrm{~mol}^{-1} \mathrm{I}^{-1}$ ). Ce type de modèle est le plus souvent utilisé pour calculer l'absorption racinaire à un pas de temps journalier. Récemment, un modèle d'absorption décrivant l'influx et l'efflux de nitrate a été proposé par Scaife (1989). II permet de simuler l'absorption nette de nitrate à l'échelle horaire, mais il n'a pas encore, à notre connaissance, été utilisé pour décrire l'absorption de plantes cultivées dans un sol. 
Le problème de l'estimation des capacités maximales d'absorption

Pour l'eau, l'estimation des capacités maximales d'absorption racinaire ne pose pas de problème particulier. Si l'approvisionnement est uniforme, on peut admettre, en l'absence de régulation stomatique, que la CARm est estimée à un instant donné par le rapport de la transpiration réelle observée, ou de l'ETP, à la longueur totale, ou au volume (Duchoslav et al, 1989), de racines. Certains auteurs (Malik et al, 1989a, b) proposent de pondérer l'efficacité racinaire par un facteur âge pour tenir compte d'une diminution de celle-ci lors du vieillissement des racines. Dans le cas général où le profil d'humidité du sol n'est pas uniforme, le sol peut être divisé en couches horizontales "homogènes", dans lesquels on considère que le flux d'absorption est proportionnel à la longueur totale des racines présentes dans la couche de sol considérée (Klepper, 1990). Pour du coton cultivé en cuve lysimétrique, Bland et Dugas (1989) ont ainsi mesuré une $\mathrm{CAR}^{\mathrm{m}}$ de $5 \mathrm{~mm}^{3}$ ( $\mathrm{mm}$ de racines) ${ }^{-1} . \mathrm{j}^{-1}$ dans la couche $1,7-1,9 \mathrm{~m}$.

II est possible que le niveau global de la demande évaporatoire soit diminué par contrôle hormonal (Giulivo, 1986; Gollan et al, 1986; Passioura, 1988). Blackman et Davies (1985) suggèrent qu'une fourniture continue de cytokinines par les racines est nécessaire pour maintenir l'ouverture stomatique : cette fourniture est perturbée lorsque les racines sont soumises à un déssèchement du sol. En même temps, la quantité d'acide abscissique produite par ces racines augmente (Zhang et Davies, 1989), et son exportation, à partir des racines situées en sol sec, peut également conduire à la fermeture des stomates dans les feuilles (Zhang et al, 1987), ou à l'augmentation de la conductance hydraulique dans le reste du système racinaire (Glinka, 1973). On illustre là combien les progrès en matière de modélisation macroscopique de l'absorption racinaire restent liés à l'approfondissement des connaissances dans le domaine de la physiologie de l'absorption de l'eau.

Un nombre très important d'études ont porté sur l'absorption du nitrate par les plantes depuis le niveau moléculaire jusqu'au niveau de la plante et du peuplement végétal (par exemple : Sébillotte, 1985; Wild et al, 1987; Barraclough, 1989; Wray, 1989). Dans une étude théorique basée sur l'utilisation du modèle de Gardner (1965), Robinson (1986) a montré que dans un sol riche en azote la CAR était un des facteurs li- mitant l'absorption racinaire. Cependant la notion de besoins en azote d'une plante pour sa croissance et son développement n'est pas encore clairement définie malgré les travaux spécifiquement réalisés pour la préciser (Coic, 1956; Greenwood, 1976; Meynard, 1985; Lemaire et Denoix, 1987a). On a pu exprimer cette demande a posteriori par la croissance en matière sèche, ou la vitesse de croissance, observée (Barnes et al, 1976; Greenwood, 1976; Habib et Monestiez, 1987), ou encore la vitesse de croissance relative en matière sèche de la plante entière (Greenwood, 1976; Ingestad, 1982).

Quand on peut considérer que le flux d'absorption minérale est une fonction linéaire de la concentration en ions à la surface racinaire (ce qui d'après l'équation 2 n'est acceptable que pour des concentrations en nitrate de l'ordre de grandeur de $K_{m}$ ), le concept selon lequel l'efficacité des racines s'adapterait pour satisfaire les besoins de la plante dans des conditions données de milieu a été formulé mathématiquement par Nye (1966), puis développé par Nye et Tinker (1969). À la base de la démarche de Nye et ses collaborateurs, il y a l'hypothèse que l'on peut définir, à une date donnée, un coefficient moyen d'efficacité des racines que l'on applique ensuite à tout le système racinaire. Ils ont montré que la demande moyenne du système racinaire root demand coefficient pouvait s'exprimer en fonction de la longueur spécitique du système racinaire (longueur de racines par unité de masse de la plante entière), du rapport de la teneur moyenne de la plante en l'élément considéré à sa concentration dans le milieu, du taux de croissance relatif en MS et du taux d'accroissement relatif de la teneur en l'élément considéré dans la plante. Cette approche a été par la suite développée par Nye et ses collaborateurs (Baldwin et al, 1973; Baldwin et Nye, 1974; Baldwin, 1975; Baldwin, 1976; Bhat et al, 1979; Nye, 1979; Bhat et Nye, 1980). Mais, à notre connaissance, elle a été peu reprise par d'autres équipes, excepté pour des objectifs de simulation (Burns, 1980; Barraclough, 1986), du fait, problablement, de la difficulté d'estimer les paramètres nécessaires à sa mise en œuvre.

Les travaux de l'école suédoise d'Ingestadt et coll réalisés sur de jeunes plants en croissance exponentielle en conditions de culture particulières où le flux d'éléments nutritifs arrivant aux racines peut être contrôlé précisément, en maintenant constante la concentration de la solution sur une large gamme, montrent cependant clairement que si l'on maintient constante la 
concentration en l'élément considéré dans la plante entière, la vitesse d'absorption relative $\left(t^{-1}\right)$ des racines est reliée linéairement au taux de croissance relatif $\left(t^{-1}\right)$ de la plante entière (voir, par exemple, la revue d'Ingestadt, 1982). Mais, en l'état actuel de nos connaissances, ces travaux semblent difficilement applicables à une plante, ou a fortiori à un peuplement, poussant au champ sur un cycle de culture : d'une part, on s'éloigne très rapidement en peuplement des conditions de croissance exponentielle, et d'autre part, le flux d'élements nutritifs vers les racines est difficile, voire impossible, à mesurer, et il faudrait en outre connaître la distribution spatiale du système racinaire.

II faut noter qu'en matière de définition des besoins en azote d'un peuplement herbacé, des progrès très significatifs ont été réalisé à partir du concept de courbe de dilution formalisé par la relation $N \%=a(M S)^{-b}$ (Lemaire et Denoix, 1987a, b; Lemaire et al, 1989). On a pu, dans ce cas, définir une courbe de référence en conditions de culture non limitante en $\mathrm{N}$ (correspondant à la notion de CARm définie au chapitre Position du problème ) qui peut être utilisée comme outil de diagnostic de la satisfaction des besoins en azote du peuplement cultivé. Des articles récents ont généralisé ce concept à un ensemble de plantes en $\mathrm{C}_{3}$ et $\mathrm{C}_{4}$ (Greenwood et al, 1990) et l'ont théorisé (Greenwood et al, 1991). Dans le cas où l'on disposerait à la fois d'une courbe de dilution de référence et d'une fonction descriptive de la dynamique de croissance du système racinaire, il devient possible de calculer une $\mathrm{CAR}^{\mathrm{m}}$ et de l'introduire dans le modèle d'absorption de l'azote.

À l'échelle de la plante, des progrès ont également été récemment réalisés dans le domaine de la régulation de l'absorption du nitrate liée à l'activité photosynthétique des parties aériennes. Ainsi, Gastal et Saugier (1989) ont montré au niveau journalier, sur des plants de fétuque cultivés en chambre de culture, que l'absorption racinaire de nitrate était proportionnelle à l'assimilation nette de carbone pour des niveaux faible ou intermédiaire de rayonnement (densité de flux de photons photosynthétiquement actifs comprise entre 200 et $400 \mu \mathrm{mol} . \mathrm{m}^{-2} . \mathrm{s}^{-1}$ ). Pour des niveaux de rayonnement plus élevés, l'absorption de $\mathrm{N}$ semblait atteindre une limite, alors que l'assimilation de $\mathrm{C}$ continuait à augmenter. Comme cela était noté par les auteurs, cette limite pourrait être déterminée par la capacité maximale d'absorption des racines (il s'agirait ici d'un maximum vrai), ou par le taux de crois- sance relatif maximal de la plante. Cette liaison absorption-photosynthèse pourrait s'effectuer par le transport de signaux métaboliques entre racines et parties aériennes, acides aminés (Cooper et Clarkson, 1989) et/ou produits de la photosynthèse (Ben Zioni et al, 1971; Touraine et al, 1988, 1990).

\section{Conséquences en matière de modélisation}

En ce qui concerne l'absorption hydrique, comme le notaient Tardieu et Manichon (1986), lorsque l'environnement est favorable, la totalité du système racinaire peut être considérée comme potentiellement fonctionnelle, et il n'y a pas de base claire pour distinguer les racines sur des critères morphologiques selon leur capacité à absorber l'eau. On ne peut encore dire si le rôle joué par la maturation des vaisseaux de métaxylème tardif chez les céréales est quantitativement suffisamment important pour devoir être pris en compte dans des modèles macroscopiques de fonctionnement. Ceci n'a été pour l'instant clairement établi expérimentalement que pour de jeunes plants âgés au plus de quelques semaines (Wenzel et al, 1989).

Novak (1987) montre, qu'en conditions non limitantes de disponibilité en eau, la fonction puits racinaire est à peu près proportionnelle à la densité de racines $\left(\mathrm{g} . \mathrm{cm}^{-3}\right)$, alors qu'en conditions limitantes elle devient plutôt proportionnelle au potentiel hydrique du sol. Ceci, associé au fait que le flux d'absorption d'eau est principalement symplasmique et que la résistance axiale est le plus souvent négligeable, montre que la $\mathrm{CAR}^{\mathrm{m}}$, dont le calcul est généralement basé sur la division de la transpiration potentielle de la plante par la longueur totale de racines (Habib et Lafolie, 1988), a bien un sens phénoménologique. Lorsque, toutes choses égales par ailleurs, c'est la disponibilité hydrique qui limite l'absorption on peut alors aisément calculer la CAR.

On pourrait également, à l'instar de Nimah et Hanks (1973), faire la distinction entre racines actives et racines inactives, mais cette distinction ne repose pas sur des bases expérimentales claires.

Il paraît donc possible de caractériser en moyenne les capacités d'absorption d'un système racinaire. L'approche macroscopique est là généralement admise. À l'inverse, il paraît illusoire, comme le notait Molz (1981), de vouloir décrire dans le détail, à l'échelle de la racine ou 
du segment de racine, les propriétés du réseau racinaire, pour reconstruire après coup le fonctionnement du système racinaire. Cela demanderait d'ailleurs d'écrire l'ensemble des équations de transfert-absorption dans un espace défini en 3 dimensions, ce qui pose des problèmes de calcul qui ne sont pas encore du domaine des ordinateurs couramment disponibles, sans parler des réelles difficultés posées par la validation expérimentale de tels modèles.

Par ailleurs, les données que nous avons présentées montrent que, pour que la continuité du processus physique soit prise en compte, l'absorption d'eau par un système racinaire doit être modélisée, à l'échelle macroscopique, par une relation proportionnelle entre le flux et le gradient de potentiel hydrique. Taylor et Klepper (1975), dans un essai sur coton cultivé sur sol sablolimoneux en rhizotron de grandes dimensions $(60 \times 120 \times 188 \mathrm{~cm})$, ont montré que l'on devait utiliser la conductance racinaire moyenne et l'introduire dans les modèles de fonctionnement définis à l'échelle macroscopique. Leur démonstration était basée sur la comparaison des absorptions hydriques estimées par deux modèles, l'un tenant compte de la conductance racinaire et l'autre non, aux valeurs d'absorptions mesurées. Certains auteurs (Lascano et van Bavel, 1984) définissent, plus globalement, le gradient de potentiel entre le sol et le feuillage, affectant à la plante entière une conductance hydraulique globale. Plus souvent cependant, c'est le potentiel racinaire qui est retenu (Molz, 1981). Deux paramètres, dépendant de la plante, sont donc généralement à introduire dans un modèle d'absorption hydrique : le potentiel et la conductance racinaire. En fait, si on se réfère à la revue de Molz (1981), peu de modèles prennent explicitement en compte ces 2 paramètres; citons cependant Hillel et al (1976), Herkelrath et al (1977), Rowse et al (1978, 1983), Reid et Hutchison (1986), Novak (1987), Protopapas et Bras (1987). Leur prise en compte systématique devrait constituer un progrès dans les futurs travaux de modélisation dans ce domaine, mais la mesure du potentiel racinaire est difficile à réaliser (Fiscus, 1972; Adeoye et Rawlins, 1981; Oosterhuis, 1987; Simonneau et Habib, 1991) et la conductance racinaire est le plus souvent estimée par l'ajustement d'un modèle de transfert d'eau dans une plante, et conditionnellement donc aux hypothèses de ce modèle.

Par ailleurs, dans un certain nombre de cas (exemple : forte demande climatique combinée à une faible disponibilité hydrique), on ne peut pas négliger la disposition spatiale des racines (Sébillotte, 1988; voir par ailleurs les articles de Tardieu déjà cités dans le texte). Cela impose d'utiliser des modèles sol-plante définis, au moins de façon bidimensionnelle (Feddes et al, 1975; Neuman et al, 1975; Lafolie et al, 1991; Bruckler et al, 1991); ce qui n'est pas sans poser per se un certain nombre de problèmes (en particulier, prise en compte du sens de variation, horizontal ou vertical, des processus et des différences d'état, difficultés de validation, accroissements des temps de calcul). De plus, un système racinaire distribué de façon hétérogène dans l'espace va induire, de par son fonctionnement même, une distribution hétérogène du champ des caractéristiques physiques du milieu qui, comme nous l'avons vu, peut conduire à une modification des capacités d'absorption des fractions du système racinaire placées dans ces conditions hétérogènes. Cela nécessite donc de pouvoir prendre en compte ces modifications de fonctionnement du système étudié, ce qui, en l'état actuel de nos connaissances et de notre savoir-faire, est encore de l'ordre du projet de recherches plutôt que de la réalisation.

Concernant l'absorption des ions, il ne paraît pas possible, en l'état actuel de nos connaissances, de proposer un modèle où apparaîtrait explicitement le moteur du flux, et l'absorption minérale ne peut être modélisée par un simple processus physique. Les modèles d'absorption actuellement utilisés à l'échelle macroscopique tentent, en fait, de relier le flux net d'absorption à des caractéristiques du système racinaire (caractéristiques géométriques et CAR) et à la disponibilité des ions dans le milieu. Les données que nous avons présentées tendent à montrer que les caractéristiques géométriques à prendre en compte pourront être, par unité de volume de sol, la masse ou longueur ou surface totale de racines pour les ions mobiles principalement absorbés par voie symplasmique. II faut noter cependant que dans un travail récent Robinson et al (1991) ont montré, dans le cas de blé de printemps cultivé en pots, que l'on ne pouvait pas considérer que l'ensemble du système racinaire était actif (qualité du contact sol-racine, ou variation physiologique de la CAR). II convient dans ce cas d'estimer la part du système racinaire active vis-à-vis de l'absorption.

Le modèle de Epstein et Hagen a été employé par de nombreux auteurs pour simuler l'absorption minérale de nombreuses cultures dans divers types de conditions expérimentales (Passioura, 1963; Kautsky et al, 1968; Nye et 
Marriott, 1969; Baldwin et al, 1972; Barnes et al, 1976; Baldwin, 1976; Burns, 1980; Novoa et Loomis, 1981; Barber et Silberbush, 1984, Barraclough, 1986; Claassen et al, 1986; Habib et Monestiez, 1987; Bar-Yosef et al, 1988; Habib et al, 1989; Lim et al, 1990). Ces modèles présentent toutefois des défauts majeurs :

- ne connaissant par le moteur des flux, ni a priori la répartition des assimilats, on calcule les paramètres d'absorption a posteriori sur la base des quantités totales absorbées (on ne peut donc pas les utiliser en simulation prédictive sensu stricto);

- ces modèles considèrent par ailleurs que les paramètres d'absorption sont constants quelle que soit la partie du système racinaire considérée et les conditions du milieu, et

- souvent, qu'ils ne varient pas au cours du temps.

Nous avons vu que ces 2 dernières hypothèses n'étaient pas acceptables dans un certain nombre de cas. Certains auteurs ont d'ailleurs proposé de moduler les capacités maximales d'absorption des racines en fonction de critères, tel, pour le nitrate, le rapport $\mathrm{C} / \mathrm{N}$ du matériel structural (Baldwin, 1976), la teneur en $\mathrm{N}$ maximale de la matière sèche produite (Barnes et al, 1976), ou encore, la teneur en nitrate du cytoplasme (Novoa et Loomis, 1981). Ces travaux sont cependant tous des travaux de modélisation où ces hypothèses de fonctionnement ont été introduites comme un paramètre supplémentaire permettant la régulation du système représenté par le modèle et son ajustement aux données, mais sans que les hypothèses physiologiques sous-jacentes en aient été directement validées.

En outre, à notre connaissance, le double mécanisme d'absorption, en fonction de la concentration en ions (Epstein, 1976; Kochian et Lucas, 1982), n'a encore jamais été introduit dans les modèles macroscopiques de fonctionnement, alors que ce serait un progrès facile à réaliser, d'autant qu'on peut montrer (Habib et Lafolie, 1988 ) que les concentrations en ions correspondantes sont aisément atteintes dans un sol après une fertilisation.

Par ailleurs, on pourrait penser introduire dans certains modèles d'absorption des ions une relation entre le flux de transpiration et le flux d'ions absorbés. Cette relation a été, et est encore, discutée, et diverses opinions peuvent être trouvées dans la littérature (Brouwer, 1965; Dalton et al, 1975; Touraine et Grignon, 1981). Ce point est à considérer dans chaque cas particulier. Dans le cas du nitrate, la littérature disponible permet plutôt de retenir l'hypothèse de la non dépendance des deux flux (Grubb, 1977; Blondel, 1979; Bhat, 1982; Schulze et Bloom, 1984; Baryosef et al, 1988; Gastal et Saugier, 1989).

Plus généralement, il faut noter, parmi les pistes les plus intéressantes concernant la régulation de l'absorption minérale, la forte sensibilité des flux ioniques à l'alimentation en glucides (Touraine et Grignon, 1981; Gastal et Saugier, 1989) et à l'équilibre hormonal (Touraine et Grignon, 1981), et l'hypothèse émise par Philipson et Coutts (1977) (cités par Atkinson, 1980), expliquant l'interdépendance fonctionnelle des différentes parties du système racinaire par une compétition pour les photosynthétats, ou encore l'hypothèse que l'on peut inférer des travaux de Touraine et al (1988) sur le rôle particulier des acides organiques produits par la photosynthèse sur la régulation de l'absorption des ions nitriques chez le soja.

\section{CONCLUSIONS}

Dans ce travail, nous avons voulu resituer les données de la littérature sur l'absorption hydrominérale sous l'éclairage particulier du fonctionnement des racines considéré à l'échelle du système racinaire. Cela nous a amené à préciser les cas où cette approche nous paraissait fondée, et à en déduire un certain nombre de conclusions en matière de modélisation macroscopique de ce phénomène et des améliorations qu'il nous paraissait possible d'apporter en restant dans le cadre que nous avions défini (cf : Modélisation de l'absorption d'eau et de nitrate à l'échelle du système racinaire). Ce cadre est bien sûr restreint, et un des objectifs de notre travail était de montrer qu'elles en étaient les limites. Celles-ci sont en fait liées à l'état des connaissances et des techniques de modélisation que l'on peut y associer.

Les mécanismes régissant l'absorption hydrominérale du système racinaire sont incomplètement connus. Au niveau tissulaire, la dualité concernant les voies d'absorption, apoplasmique ou symplasmique, et les mécanismes mis en jeu, actifs ou passifs, sont encore, pour certains, discutés. Et les paramètres de cinétique d'absorption et de croissance ne sont ni constants, ni homogènes au sein du système racinaire qui apparaît comme étant doué d'une plasticité de 
fonctionnement. D'importants progrès sont à réaliser qui permettraient de mieux comprendre, au niveau de la plante, ces régulations de fonctionnement.

Dans ce champ thématique, la tâche impartie à l'agronome est double «bâtir et utiliser des modèles qui simulent correctement le comportement global sans pour autant le comprendre dans ses mécanismes intimes", mais aussi "étudier l'effet de certains d'entre eux, grâce à la méthode expérimentale" (Sebillotte, 1974). Il s'agit souvent d'expliquer a postériori par des modèles jugés par leurs capacités à diminuer la variance résiduelle des données expérimentales. II est clair que ces modèles auront d'autant plus de chances d'y parvenir que les hypothèses émises pour les construire seront basées sur des connaissances acquises sur le fonctionnement du système étudié, mais également, sur des travaux plus sectoriels, pour autant que les résultats obtenus en soient intégrables à l'échelle considérée. Cela pose finalement la question du choix des variables pertinentes et accessibles à introduire dans un modèle, et de la définition des variables de commande du système étudié.

\section{RÉFÉRENCES}

Abbott JD, Cough RE (1986) Split-root water application to highbush blueberry plants. Hortscience 21, 997-998

Adeoye KB, Rawlins SL (1981) A split-root technique for measuring root water potential. Plant Physiol 68, 44-47

Anderson WP (1975) Ion transport through roots. In: The development and functions of roots, Torrey JG, Clarkson DT (eds), Acad Press Londres, 437-463

Atkinson (1974) Some observations on the distribution of root activity in apple trees. Plant Soil 40, 333-342

Atkinson D (1980) The distribution and effectiveness of the roots of tree crops. Hort Rev 424-490

Atkinson D (1985) The nutrient requirements of fruit trees: some current considerations. In: Adv in Plant Nutr (PB Tinker, A Laudli, eds) Vol (2), 93-128

Baldwin JP (1975) A quantitative analysis of the factors affecting plant nutrient uptake from some soils. J Soil Sci 26, 195-206

Baldwin JP (1976) Competition for nutrient in soils; a theoritical approach. J Agric Sci Camb 87, 341-356

Baldwin JP, Nye PH (1974) A model to calculate the uptake by a developing root system or root hair systems of solutes with concentration variable diffusion coefficients. Plant Soil 40, 703-706

Baldwin JP, Tinker PB, Nye PH (1972) Uptake of solutes by multiple root systems from soil. II. The theo- retical effects of rooting density and pattern on uptake of nutrients from soil. Plant Soil 36, 693-708

Baldwin JP, Nye PH, Tinker PB (1973) Uptake of solutes by multiple root systems in soil. III. A model for calculating the solute uptake by a randomly dispersed root system developing in a finite volume of soil. Plant Soil 38, 621-635

Barber SA, Silberbush HM (1984) Plant root morphology and nutrient uptake. In: Roots, nutrient and water influx and plant growth. ASA Special publ 49, 65-87

Barley KP (1970) The configuration of the root system in relation to nutrient uptake. Adv Agron 22, 159201

Barnes A, Greenwood DJ, Cleaver TJ (1976) A dynamic model for the effects of potassium and nitrogen fertilizers on the growth and nutrient uptake of crops. J Agric Sci Camb 86, 225-244

Barraclough PB (1986) The growth and activity of winter wheat roots in the field: nutrient inflows of highyielding crops. J Agric Sci Camb 106, 53-59

Barraclough PB (1989) Root growth and nutrient uptake by field crops under temperate conditions. Asp Appl Biol 22, 227-233

Bar-Yosef B, Schwartz S, Markovich T, Lucas B, Assaf R (1988) Effect of root volume and nitrate solution concentration on growth, fruit yield, and temporal $\mathrm{N}$ and water uptake rates by apple trees. Plant Soil 107, 49-56

Ben Zioni A, Vaadia Y, Lips SH (1971) Nitrate uptake by roots as regulated by nitrate products of the shoot. Physiol Plant 24, 288-290

Bhat KKS (1982) Nutrient inflows into apple roots. II. Nitrate uptake rates measured on intact roots of mature trees under field conditions. Plant Cell Environ 5, 461-469

Bhat KKS (1983) Nutrient inflows into apple roots. Plant Soil 71, 371-380

Bhat KKS, Nye PH (1980) Plant attributes involved in the nitrate absorbing power of roots. $J$ Sci Food Agric 31, 851-852

Bhat KKS, Brereton AJ, Nye PH (1979) The possibility of predicting solute uptake and plant growth response from independently measured soil and plant characteristics. VII. A comparison of the growth and nitrate uptake of rape grown in similar nitrate concentration in solution or in soil solution. Plant Soil 53, 193-201

Blackman PG, Davies WJ (1985) Root to shoot communication in maize plants and the effects of soil drying. J Exp Bot 36, 39-48

Blanchet R, Maertens C, Bosc M (1974) Principaux facteurs agronomiques déterminant l'absorption des éléments nutritifs par les racines. Sci Sol 69-79

Bland WJ, Dugas WA (1989) Cotton root growth and soil water extraction. Soil Sci Soc Am J 53, 1850 1855

Blondel AM (1979) Dynamique comparée de l'absorption des nitrates et de l'eau par des plantules de 
blé. CR Seances Acad Sci Paris 288, sér D, 15451548

Bosc M (1981) Participation des divers états du phosphore et du potassium du sol à l'alimentation des plantes. Implications sur le diagnostic de la fertilité des sols. In: Critère de fertilité des sols et d'évolution de cette fertilité en fonction des systèmes de culture, Séminaire CEE-Agrimed, Bari (Italie), 2829 Septembre 1981, 121-139

Bosc M, Maertens C (1981) Rôle de l'accroissement du système racinaire dans l'absorption de divers états du potassium du sol. Agrochimica 25, 1-8

Boyer JS (1985) Water transport. Ann Rev Plant Physiol 36, 473-516

Breteler H, Nilsen P (1982) Effect of exogenous and endogenous nitrate concentration on nitrate utilization by dwarf bean. Plant Physiol 70, 754-759

Brewster JL, Tinker PBH (1972) Nutrient flow rates into roots. Soils Fert 35, 335-359

Briggs GM, Wiebe HH (1982) The effects of root pruning on the water relations of Helianthus annuus $\mathrm{L}$. $J$ Exp Bot 33, 966-976

Brouwer R (1953) Water absorption by the roots of Vicia faba at various transpiration strengths. I. Analysis of the uptake and the factors determining it. Proc K Ned Akad Wet, C56, 106-115

Brouwer R (1954) Water absorption by the roots of Vicia faba at various transpiration strengths. III. Changes in water conductivity artificially obtained. Proc K Ned Akad Wet C57, 68-80

Brouwer R (1965) lon absorption and transport in plants. Annu Rev Plant Physiol 16, 241-266

Brouwer R (1981) Coordination of growth phenomena within a root system of intact maize plants. In: Structure and function of plant roots, Brouwer SR et al (ed), Nijhoff, Junk, La Haye, Boston, Londres, 269-276

Brouwer R (1983) Functional equilibrium: sense or monsense? Neth J Agric Sci 31, 335-348

Brouwer R, De Wit CT (1969) A simulation model of plant growth with special attention to root growth and its consequences. In: Root Growth (WJ Whittington, ed), Butterworths, Londres, 224-244

Bruckler L, Lafolie F, Tardieu F (1991) Modeling root water potential and soil-root water transport. 2. Field compaigns. Soil Sci Soc Am J (sous presse)

Burns IG (1980) Influence of the spatial distribution of nitrate on the uptake of $\mathrm{N}$ by plants: a review and a model for rooting depth. $J$ Soil Sci 31, 155-173

Callot G, Chamayou H, Maertens C, Salzac L (1982) Les interactions sol-racines. Incidence sur la nutrition minérale. INRA, Paris, $325 \mathrm{p}$

Cannon WA (1949) A tentative of classification of root systems. Ecology 30, 542-548

Claassen N, Barber SA (1977) Potassium influx characteristics of corn roots and interaction with $N, P$, $\mathrm{Ca}$ and $\mathrm{Mg}$ influx. Agron J69, 860-864

Claassen N, Syring KM, Jungk A (1986) Verification of a mathematical model by simulating potassium uptake from soil. Plant Soil 95, 209-220
Clarkson DT (1968) lon uptake and root age. Nature 220, 805-806

Clarkson DT (1985) Factors affecting mineral acquisition by plants. Annu Rev Plant Physiol 36, 77-115

Clarkson DT, Robards AW (1975) The endodermis. Its structural development and physiological role. In: The development and functions of roots (Torrey JG, Clarkson DT, eds) Acad Press, Londres, 415-434

Clarkson DT, Hanson JB (1980) The mineral nutrition of higher plants. Annu Rev Plant Physiol 31, 239298

Coic $Y$ (1956) La nutrition et la fertilisation azotées du blé d'hiver. I. Les besoins en azote du blé d'hiver. Conséquences agronomiques. Ann Agron 6, 115131

Cooper HD, Clarkson DT (1989) Cycling of aminonitrogen and other nutrients between shoots and roots in cereals. A possible mechanism integrating shoot and root in regulation of nutrient uptake. $J$ Exp Bot 40, 753-762

Daie J (1985) Carbohydrate partitioning and metabolism in crops. Hortic Rev 7, 69-108

Dainty I, Kleinova M, Janacek K (1981) The movement of water across the plant root. In: Structure and function of plant roots, Brouwer SR et al (eds), Nijhoff, Junk, The Hague, Boston, London, 149-152

Dalton FN, Raats PAC, Gardner WR (1975) Simultaneous uptake of water and solutes by plant roots. Agron J 67, 334-339

Diggle AJ (1988) ROOTMAP - a model in threedimensional coordinates of the growth and structure of fibrous root systems. Plant Soil 105, 169-178

Drew MC (1975) Comparison of the effects of a localized supply of phosphate, nitrate, ammonium and potassium on the growth of the seminal root system, and the shoot in barley. New Phytol 75, 479490

Drew MC, Saker LR (1975) Nutrient supply and the growth of the seminal root system in barley. II. Localised compensatory increases in lateral root growth and rates of nitrate uptake when $\mathrm{NO}_{3}^{-}$is restricted to only part of the root system. J Exp Bot 26, 79-80

Drew MC, Saker LR (1978) Nutrient supply and the growth of the seminal root system in barley. III. Compensatory increase in growth of lateral roots, and in rates of phosphate uptake, in response to a localised supply of phosphate. J Exp Bot 29, 435451

Duchoslav S, Navara J, Jesko T (1989) Role in water uptake by maize seedlings of volume, surface area and dry weight of the root system. Biologia (Brastislava) 44, 819-826

Edwards JH, Barber SA (1976) Nitrogen flux into corn roots as influenced by shoot requirement. Agron $J$ 68, 471-473

Epstein E (1976) Kinetics of ion transport and the carrier concept. In: Encyclopedia of Plant Physiology, Luttge W (ed), Springer Verlag (Berlin), 2B, 70-94 
Epstein E, Hagen CE (1952) A kinetic study of the absorption of alkali cations by barley roots. Plant Physiol $27,457-474$

Ernst M, Römheld V, Marschner H (1989) Estimation of phosphorus uptake capacity by different zones of primary root of soil-grown maize (Zea mays L). $Z$ Pflanzenernaehr Bodenkde 152, 21-25

Feddes RA, Neuman SP, Bresler E (1975) Finite element analysis of two-dimensional flow in soils considering water uptake by roots. II. Field applications. Soil Sci Soc Am Proc 39, 231-237

Ferguson IB, Clarkson DT (1975) lon transport and endodermal suberization in the roots of Zea mays. New Phytol 75, 69-79

Fiscus EL (1972) In situ measurement of root-water potential. Plant Physiol 50, 191-193

Fiscus EL (1977) Determination of hydraulic and osmotic properties of soybean root system. Plant Physiol 59, 1013-1020

Fitter AH (1986) The topology and geometry of plant root systems: influence of watering rate on root system topology in Trifolium pratense. Ann Bot 58, 91101

Fitter AM (1987) An architectural approach of the comparative ecology of plant root systems. New Phytol 106 (suppl) s61-s77

Foehse D, Jungk A (1983) Influence of phosphate and nitrate supply on root hair formation of rape, spinach and tomato plants. Plant Soil 74, 359-368

Fowkes ND, Landsberg JJ (1981) Optimal root systems in terms of water uptake and movement. In: Mathematics and Plant Physiology (DA Rose, DA Charles-Edwards, eds), Acad Press, Londres, 109125

Frith GJT, Nichols DG (1975) Nitrogen uptake by apple seedlings as affected by light, and nutrient stress in part of the root system. Physiol Plant 34, 129-133

Gachon L (1988) Phosphore et potassium and les relations sol-plante : conséquences sur la fertilisation (Gachon L, ed), INRA, $566 \mathrm{p}$

Gardner WR (1965) Movement of nitrogen in soil. In: Soil Nitrogen (Barthelomew WV et Clarks FE, eds), Am Soc Agron, Madison, 550-572

Gastal F, Saugier B (1989) Relationships between nitrogen uptake and carbon assimilation in whole plants of tall fescue. Plant Cell Environ 12, 407-416

Girardin P, Jordan MO, Picard D, Trendel R (1986) Harmonisation des notations concernant la description morphologique d'un pied de maïs (Zea mays $L$ ). Agronomie 6, 873-875

Giulivo C (1986) Hormonal control of water transport in soil-plant-atmosphere continuum. Acta Hortic 179, 385-393

Glinka Z (1973) Abscissic acid effect on root exudation related to increased permeability to water. Plant Physiol 51, 217-219

Gollan T, Passioura JB, Munns R (1986) Soil water status affects the stomatal conductance of fully tur- gid wheat and sunflower leaves. Aust J Plant Physiol 13, 459-464

Grasmanis VO, Nicholas DJD (1971) Annual uptake and distribution of $15 \mathrm{~N}$-labelled ammonium and nitrate in young Jonathan/MM 104 apple trees grown in solution cultures. Plant Soil 35, 95-112

Greewood EAN (1976) Nitrogen stress in plants. Adv Agron 28, 1-35

Greenwood DJ, Gerwitz A, Stone DA, Barnes A (1982) Root development of vegetable crops. Plant Soil $68,75-96$

Greenwood DJ, Lemaire G, Gosse G, Cruz P, Draycoot A, Neeteson JJ (1990) Decline in percentage $\mathrm{N}$ of $\mathrm{C}_{3}$ and $\mathrm{C}_{4}$ crops with increasing plant mass. Ann Bot 66, 425-436

Greenwood DJ, Gastal F, Lemaire G, Draycott A, Millard P, Neeteson JJ (1991) Growth rate and \%N of field grown crops: Theory and Experiments. Ann Bot 67, 181-190

Grignon C, Touraine B (1981) Les fonctions de transport de la racine. I. Les fonctions de prélèvement. Physiol Veg 19, 443-462

Grubb PJ (1977) Control of forest growth and distribution on wet tropical mountains: with special reference to mineral nutrition. Annu Rev Ecol Syst 8, 83-107

Habib (1987) Effet de la disponibilité en nitrate sur le comportement de jeunes pêchers en culture hydroponique. Agronomie 7, 101-109

Habib R (1988) Quelques réflexions concernant les problèmes de fertilisation en cultures irriguées. Fruits 43, 381-390

Habib R, Monestiez P (1987) Modélisation de la dynamique de répartition de l'azote chez un jeune arbre fruitier pendant la phase de croissance exponentielle. I. Établissement du modèle. Estimation de paramètres. Agronomie 7, 401-408

Habib R, Lafolie F (1991) Water and nitrate redistribution in soil as affected by root distribution and absorption. Symposium Plant root systems: Their effects on ecosystem composition and structure (D Atkinson, ed), Blackwell Sci Publ, Oxford (sous presse)

Habib R, de Cockborne AM, Monestiez P, Lafolie F (1989) An experimental test of a nitrogen uptake and partitioning model for young trees. Tree Physiol 5, 403-421

Hackett C (1969) A study of the root system of barley. II. Relationships between root dimensions and nutrient uptake. New Phytol 68, 1023-1030

Hacket C (1972) A method of applying nutrients locally to roots under controlled conditions, and some morphological effects of locally applied nitrate on the branching of wheat roots. Aust $J$ Biol Sci 25, 1169-1180

Hamblin A, Tennant D (1987) Root length density and water uptake in cereals and grain legumes: How well are they correlated? Aust J Agric Res 38, 513527 
Hansen GK (1974) Resistance to water transport in soil and young wheat plants. Acta Agric Scand 24, 37-48

Hanson PJ, Sucoff El, Markhart AH (1985) Quantifying apoplastic flux through red pine root systems using trisodium, 3-hydroxy-5,8,10-pyrenetrisulfonate. Plant Physiol 77, 21-24

Herkelrath WN, Miller EE, Gardner WR (1977) Water uptake by plants. 2. The root contact model. Soil Sci Soc Am J 41, 1039-1043

Hillel D, Talpaz H, van Keulen $H$ (1976) A macroscopic-scale model of water uptake by a nonuniform root system and of water and salt movement in the soil profile. Soil Sci 121, 242-255

Huang CX, van Steveninck RFM (1988) Effect of moderate salinity on patterns of potassium, sodium and chloride accumulation in cells near the root tip of barley: Role of differentiating metaxylem vessels. Physiol Plant 73, 525-533

Ingestad T (1982) Relative addition rate and external concentration; driving variables used in plant nutrition research. Plant Cell Environ 443-453

de Jager A (1982) Effects of localized supply of $\mathrm{H}_{2} \mathrm{PO}_{4}, \mathrm{NO}_{3}, \mathrm{SO}_{4}, \mathrm{Ca}$ and $\mathrm{K}$ on the production and distribution of dry matter in young maize plants. Neth J Agric Sci 30, 193-203

de Jager A (1984) Effects of a localized supply of $\mathrm{H}_{2} \mathrm{PO}_{4}, \mathrm{NO}_{3}, \mathrm{SO}_{4}, \mathrm{Ca}$ and $\mathrm{K}$ on the concentration of that nutrient in the plant and the rate of uptake by roots in young maize plants in solution culture. Neth J Agric Sci 32, 43-56

Jordan MO (1987) Mise en place du système racinaire du maïs. Il. Importance de quelques paramètres relatifs aux conditions de milieu. Agronomie 7, 457465

Jungk A, Claassen N (1989) Availability in soil and acquisition by plants as the basis for phosphorus and potassium supply to plants. $Z$ Pflanzennernaehr Bodenkd 152, 151-157

Kaustky J, Barley KP, Fiddaman DK (1968) Ion uptake from soils by plant roots, subject to the Epstein-Hagen relation. Aust J Soil Res 6, 159-167

Kirkham MB, Gardner WR, Gerloff GC (1969) Leaf water potential of differentially salinized plants. Plant Physiol 44, 1378-1382

Klepper B (1990) Root growth and water uptake. In: Irrigation of Agricultural Crops, Agronomy monograph, 30, 281-322

Kochian LV, Lucas WJ (1982) Potassium transport in plant corn roots. I. Resolution of kinetics into a saturable and linear component. Plant Physiol 70, 1723-1731

Kuiper D (1983) Genetic differentiation in Plantago major. growth and root respiration and their role in phenotypic adaptation. Physiol Plant 57, 222-230

Lafolie F, Bruckler L, Tardieu F (1991) Modeling root water potential and soil-root water transport. 1. Model presentation. Soil Sci Soc Am J (sous presse)
Lambers H, Szaniawski RK, de Visser R (1983) Respiration for growth, maintenance and ion uptake. An evaluation of concepts, methods, values and their significance. Physiol Plant 58, 556-563

Lascano RJ, van Bavel CHM (1984) Root water uptake and soil water distribution: test of an availability concept. Soil Sci Soc Am J 48, 233-237

Lassales JP, Thellier M (1974) Modèles théoriques utilisables pour la description des échanges cellulaires. Physiol Vég 12, 665-688

Lawlor DW (1973) Growth and water absorption of wheat with parts of the roots at different water potentials. New Phytiol 72, 297-305

Lemaire G, Denoix A (1987a) Croissance estivale en matière sèche de peuplement de fétuque élevée (Festuca arundinacea Schreb) et de dactyle (Dactylis glomerata L) dans l'ouest de la France. I. Étude en conditions de nutrition azotée et d'alimentation hydrique non limitantes. Agronomie 7, 373-380

Lemaire G, Denoix A (1987b) Croissance estivale en matière sèche de peuplement de fétuque élevée (Festuca arundinacea Schreb) et de dactyle (Dactylis glomerata L) dans l'ouest de la France. II. Interaction entre les niveaux d'alimentation hydrique et de nutrition azotée. Agronomie 7, 381-389

Lemaire G, Gastal F, Salette J (1989) Analysis of the effect of $N$ nutrition on dry matter yield of a sward by reference to potential yield and optimum $N$ content. XVI International Grassland Congress, Nice, France, 179-180

Lim JT, Wilkerson GG, Raper Jr CD, Harvey JG (1990) A dynamic growth model of vegetative soya bean plants: model structure and behaviour under varying root temperature and nitrogen concentration. J Exp Bot 41, 229-241

Mac Cully ME, Canny MJ (1988) Pathways and processes of water and nutrient movement in roots. Plant Soil 111, 159-170

Mac Cully ME, Canny J, Van Steveninck RFM (1987) Accumulation of potassium by differentiating metaxylem elements of maize roots. Physiol Plant 69 , $73-80$

Maertens C (1971a) Étude expérimentale de l'alimentation minérale et hydrique du maiis. Capacité d'absorption des parties basales et apicales de racines de Zea mays. CR Seances Acad Sci Paris, Sér D, 273, 730-732

Maertens C (1971b) Étude expérimentale de l'alimentation minérale et hydrique du maïs. Comparaison des besoins de la plante et des possibilités d'absorption d'azote, de phosphore et de potassium par les racines de Zea mays. CR Seances Acad Sci Paris, Sér D, 273, 682-684

Maertens C (1978) Possibilités d'absorption des éléments minéraux par les racines. Conséquences sur la localisation. Sci Sol 3, 185-195

Maertens C, Clauzel Y (1975a) Influence de la teneur en potassium de jeunes plants de Zea mays sur l'absorption de cet élément par les racines. $C R$ Acad Sci Paris, Sér D, 280, 841-843 
Maertens C, Clauzel Y (1975b) Influence de la teneur en azote de jeunes plants de Zea mays sur l'absorption des nitrates par les racines. CR Seances Acad Sci Paris, Sér D, 280, 981-982

Maertens C, Clauzel $Y$ (1980) Rôle du flux de sève brute dans les racines sur l'absorption de l'azote nitrique, du potassium et du calcium par les systèmes racinaires de jeunes plantes de Zea mays. CR Acad Séances Sci Paris, Sér D, 290, 1285-1287

Malik RK, Murty VVN, Narda NK (1989a) Macroscopic scale soil moisture dynamics model for a wheat crop. Irrig Sci 10, 141-151

Malik RK, Narda NK, Murty VVN (1989b) Development and testing of root effectiveness function for soil water uptake. J Agron Crop Sci 162, 135-140

Marschner H (1990) Mobilization of mineral nutrients in the rhizosphère. In: Proc First Congress of the European Society of Agronomy (A Scaife, ed) ESA, Colmar, session 3, O 00, $11 \mathrm{p}$

May LH, Chapman FH, Aspinall D (1965) Quantitative studies of root development. I. The influence of nutrient concentration. Aust J Biol Sci 18, 25-35

Meyer MS, Alston AM (1978) Wheat responses to seminal root geometry and subsoil water. Agron $\mathrm{J} 70$, 981-986

Meynard JM (1985) Les besoins en azote du blé d'hiver jusqu'au début de la montaison. Agronomie 5, 579-589

Michel BE, Eisharkawi JM (1970) Investigation of plant water relations with divided root systems of soybean. Plant Physiol 46, 728-731

Molz FJ (1981) Models of water transport in the soilplant system: A review. Water Resour Res 17, 1245-1260

Morizet J, Cruiziat P, Falcimagne R (1988) Variation de la résistance au transfert de l'eau dans les racines de tournesol (Helianthus annuus L). Étude sur système racinaire fractionné. CR Séances Acad Sci Paris, Sér II/ 306, 345-350

N'DaKouassi A, Puard M (1989) Relations hydriques de deux types variétaux de riz soumis à un traitement osmotique. Plant Physiol Biochem 27, 119125

Neuman SP, Feddes RA, Bresler E (1975) Finite element analysis of two-dimensional flow in soils considering water uptake by roots. I. Theory. Soil Sci Soc Am Proc 37, 522-527

Newman El (1973) Permeability to water of the roots of five herbaceous species. New Phytol 72, 547-555

Nielson NE, Barber SA (1978) Differences among genotypes of corn in the kinetics of $P$ uptake. Agron $J$ 70, 695-698

Nimah MN, Hanks RJ (1973) Model for estimating soil water, plant and atmospheric interrelations. 1. Description and sensitivity. Soil Sci Soc Am Proc 37, 522-527

Ningping L, Barber SA (1985) Phosphorus uptake rate and growth characteristics of wheat roots. J Plant Nutr 8, 449-456
Nissen $P$ (1989) Multiphasic uptake of potassium by corn roots. No linear components. Plant Physiol 89 . $231-237$

Novak V (1987) Estimation of soil-water extraction patterns by roots. Agric Water Manage 12, 271-278

Novoa R, Loomis RS (1981) Modelo dinamico del metabolismo del nitrogeno en plantas superiores. I. Descripcion del modelo. Agricultura Tec (Santiago) 41, 41-48

Nye PH (1966) The effect of the nutrient intensity and buffering power of a soil, and the absorbing power, size and root hairs of a root, on nutrient absorption by diffusion. Plant Soil 25, 81-105

Nye PH (1979) Soil properties controlling the supply of nutrients to the root surface. In: The soil-root interface (JL Harley, RS Russel, eds), Acad Press, Londres, 39-49

Nye PH, Marriott FHC (1969) A theoretical study of the distribution of substances around roots resulting from simultaneous diffusion and mass flow. Plant Soil 30, 459-472

Nye PH, Tinker PB (1969) The concept of a root demand coefficient. J App/ Eco/6, 293-300

Oosterhuis DM (1987) A technique to measure the components of root water potential using screencaged thermocouple psychrometers. Plant Soil $103,285-288$

Pages L (1988) Morphogenèse racinaire. Aspects particuliers chez les arbres. In: $8^{e}$ Colloque sur les recherches fruitières, INFA-CTIFL, Bordeaux 7-8 Décembre 1988, 81-92

Pages L, Aries F (1987) Modélisation de l'architecture des systèmes racinaires. Présentation d'un modèle mathématique de simulation. In: $7^{e}$ Colloque sur les recherches fruitières, INRA-CTIFL, Bordeaux 23 décembre 1987, 177-189

Pages L, Aries F (1988) SARAH : Modèle de simulation de la croissance, du développement et de l'architecture des systèmes racinaires. Agronomie 8 , 889-896

Pages L, Jordan MO, Picard D (1989) A simulation model of the three-dimensional architecture of the maize root system. Plant Soil 119, 147-154

Papadopoulos I, Rendig VV, Broadbent FE (1985) Growth, nutrition and water uptake of tomato plants with divided roots growing in differentially salinized soil. Agron J 77, 21-26

Passioura JB (1963) A mathematical model for the uptake of ions from the soil solution. Plant Soil 18, 225-238

Passioura JB (1972) The effect of root geometry on the yield of wheat growing on stored water. Aust $J$ Agric Res 23, 745-752

Passioura JB (1974) The effect of root geometry on the water relations of temperate cereals. In: Structure and functions of primary root tissues, Proc Symposium Tatranska Lomnica (Kolek J, ed), 357363

Passioura JB (1988) Water transport in and to roots. Annu Rev Plant Physiol Plant Mol Biol 39, 245-265 
Philipson JJ, Coutts MP (1977) The influence of mineral nutrition on the root development of stress. $J$ Exp Bot 28, 864-871

Picard D (1988) Dynamique racinaire et interception des éléments minéraux par les racines. $C R$ Séances Acad Agric Fr 74, 5-14

Protopapas AL, Bras RL (1987) A model for water uptake and development of root systems. Soil Sci 144, 352-366

Rao KP, Rains DW (1976) Nitrate absorption by barley. I. Kinetics and energetics. Plant Physiol 57, 5558

Reid JB, Hutchison B (1986) Soil and plant resistances to water uptake by Vicia faba L. Plant Soil $92,431-441$

Robinson D (1986) Limits to nutrient inflow rates in roots and root systems. Physiol Plant 68, 551-559

Robinson D, Rorison IH (1983) Relationships between root morphology and nitrogen availability in a recent theorical model describing nitrogen uptake from soil. Plant Cell Environ 6, 641-647

Robinson D, Linehan DJ, Caul S (1991) What limits nitrate uptake from soil? Plant Cell Environ 14, 77-85

Rowse HR, Stone DA, Gerwitz A (1978) Simulation of the water distribution in soil. 2 . The model for cropped soil and its comparison with experiments. Plant Soil 49, 534-550

Rowse HR, Mason WK, Taylor HM (1983) A microcomputer modet of soil water extraction by soybeans. Soil Sci 136, 218-225

Russel RS, Clarkson DT (1971) The uptake and distribution of potassium in crop plants. In: Potassium in biochemistry and physiology, 8th colloquium of the Int Potash Inst Int Potash Inst, Berne, 79-92

Russel RS, Barber DA (1960) The relationship between salt uptake and the absorption of water by intact plants. Annu Rev Plant Physiol 11, 127-140

Russel RS, Sanderson J (1967) Nutrient uptake by different parts of the intact roots of plants. $J$ Exp Bot $18,491-508$

Russel RS, Clarkson DT (1976) lon transport in root systems. In: Perspectives in experimental Biology. Botany, Pergamon Press, Oxford 2, 401-411

Sands R, Fiscus EL, Reid CPP (1982) Hydraulic properties of pine and bean roots with varying degrees of suberization, vascular differentiation and mycorrhizal infection. Aust J Plant Physiol 9, 559-569

Scaife A (1989) A pump/leak/buffer model for plant nitrate uptake. Plant Soil 114, 139-141

Schulze ED, Bloom AJ (1984) Relationship between mineral nitrogen influx and transpiration in radish and tomato. Plant Physiol 76, 827-828

Sébillotte M (1974) Agronomie et agriculture. Essai d'analyse des tâches de l'agronome. Cah ORSTOM, Sér Biol 24, 3-25

Sébillotte M (1985) Rôle de l'azote dans le comportement d'un peuplement de céréales. Réflexions sur les approches de l'agronome. CR Acad Agric Fr 71 , 292-301
Sébillotte M (1988) Les transferts d'eau sol-système racinaire. In: Études sur les transferts d'eau dans le système sol-plante-atmosphère ( $R$ Calvet, ed), INRA, Paris, 171-179

Simonneau T, Habib R (1990) Transferts d'eau ches de jeunes pêchers cultivés en solution nutritive. Effets d'un stress hydrique par émersion partielle de racines. In: Effets physiologiques de stress tels que sécheresse, ablations, défoliations et transplantations, Réunion du groupe d'étude de l'arbre, Nancy, 27-28 mars 1990, Centre de Recherches INRA de Nancy, Résumé

Simonneau T, Habib R (1991) The use of tree root suckers to estimate the root water potential. Plant Cell Environ 14 (sous presse)

Smith E, Gianinazzi-Pearson V (1988) Physiological interactions between symbionts in vesiculararbuscular mycorrhizal plants. Annu Rev Plant Physiol Plant Mol Biol 39, 221-244

Steudle E (1989) Water transport in roots. In: Structural and functional aspects of transport in roots (BC Loughman et al, eds), Kluwer Acad Publ Dordrecht, 139-145

Swietlik D (1989) Pressure-induced water fluxes through root systems of sour orange seedlings. J Am Soc Hortic Sci 114, 139-143

Tan CS, Cornelisse A, Buttery BR (1981) Transpiration, stomatal conductance, and photosynthesis of tomato plants with proportions of root system supplied with water. J Am Soc Hortic Sci 106, 147-151

Tardieu F (1984) Étude au champ de l'enracinement du maïs. Influence de l'état structural sur la répartition des racines. Conséquences sur l'alimentation hydrique. Thèse INA-PG, Paris, $232 p$

Tardieu F (1987) État structural et enracinement du maïs. III. Disponibilité des réserves en eau du sol. Agronomie 7, 279-288

Tardieu F (1988a) Conséquences de la disposition spatiale des racines au champ sur les transferts d'eau sol-plante. In: Études sur les transferts d'eau dans le système sol-plante-atmosphère ( $R$ Calvet, ed) INRA, Paris, 181-211

Tardieu F (1988b) Analysis of the spatial root density in maize root density. III. Effect of a wheel compaction on water extraction. Plant Soil 109, 257-262

Tardieu F, Manichon H (1986) Caractérisation en tant que capteur d'eau de l'enracinement du maïs en parcelle cultivée. I. Discussion des critères d'étude. Agronomie 6, 345-354

Tardieu F, Manichon H (1987) État structural, enracinement et alimentation hydrique du maïs. II. Croissance et disposition spatiale du système racinaire. Agronomie 7, 201-211

Taylor HM, Klepper B (1974) Water relations of cotton root growth and water use as related to top growth and soil water content. Agron J 66, 584-588

Taylor HM, Klepper B (1975) Water uptake by cotton root systems: and examination of assumptions in the single root model. Soil Sci 120, 57-67 
Taylor HM, Klepper B (1978) Role of rooting characteristics. Adv Agron 30, 99-128

Teskey RO, Grier CC, Hinckley TT (1985) Relation between root system size and water inflow capacity of Abies growing in a subalpine forest. Can $J$ For Res 15, 669-672

Torrey JG, Wallace WD (1975) Further studies on primary vascular tissue pattern formation in roots. In: The development and function of roots (Torrey JG and Clarkson DE, eds) Acad Press, Londres, 91103

Touraine B, Grignon C (1981) Les fonctions de transport de la racine. II. Les fonctions d'exportation. Physiol Vég 19, 581-610

Touraine B, Grignon N, Grignon C (1988) Charge balance in $\mathrm{NO}_{3}^{-}$-fed soybean. Estimation of $\mathrm{K}^{+}$and carboxylate recirculation. Plant Physiol 88, 605-612

Touraine B, Grignon N, Grignon C (1990) Interaction between nitrate assimilation in shoots and nitrate uptake by roots of soybean (Glycine max) plants: Role of carboxylate. Plant Soil 124, 169-174

Vartanian N (1975) Diversité morphologique du système racinaire en relation avec l'humidité édaphique. In: Compte rendu des séminaires du groupe d'étude des racines (Gagnaire Michard J, Riedacker A, eds) CEA, Grenoble, INRA, Nancy, Tome 2, 166179

Vartanian N (1981) Some aspects of structural and functional modifications induced by drought in root systems. Plant Soil 63, 83-92

Wallach D, Loisel P, Goffinet B, Habib R (1990) Modelling the time dependence of nitrogen uptake in young trees. Agron J 82, 1135-1140
Weatherley PE (1975) Water relations of the root systems. In: The development and functions of roots (Torrey JG, Clarkson DT, eds), Acad Press, Londres, 397-417

Weinbaum SA, Mervin ML, Muraoka TT (1978) Seasonal variation in nitrate uptake efficiency and distribution of absorbed nitrogen in non-bearing prune trees. J Am Soc Hortic Sci 103, 516-519

West DW (1978a) Water use and sodium chloride uptake by apple trees. 1. The effect of non-uniform sodium chloride in the root zone. Plant Soil 50, 3749

West DW (1978b) Water use and sodium chloride uptake by apple trees. 2 . The response to soil oxygen deficiency. Plant Soil 50, 51-65

Wenzel CL, McCully ME, Canny MJ (1989) Development of water conducting capacity in the root systems of young plants of corn and some other $\mathrm{C}_{4}$ grasses. Plant Physiol 89, 1094-1101

Wild A, Jones LHP, Macduff JH (1987) Uptake of mineral nutrients and crop growth: The use of flowing solutions. Adv Agron 41, 171-219

Wray JL (1989) Towards the molecular characterization of nitrate uptake in higher plants. Asp Appl Biol $22,357-363$

Zhang J, Davies WJ (1989) Abscisic acid produced in dehydrating roots may enable the plant to measure the water status of the soil. Plant Cell Environ 12, 73-81

Zhang J, Schurr U, Davies WJ (1987) Control of stomatal behaviour by abscisic acid which apparently originates in the roots. $J$ Exp Bot 38, 1174-1181 